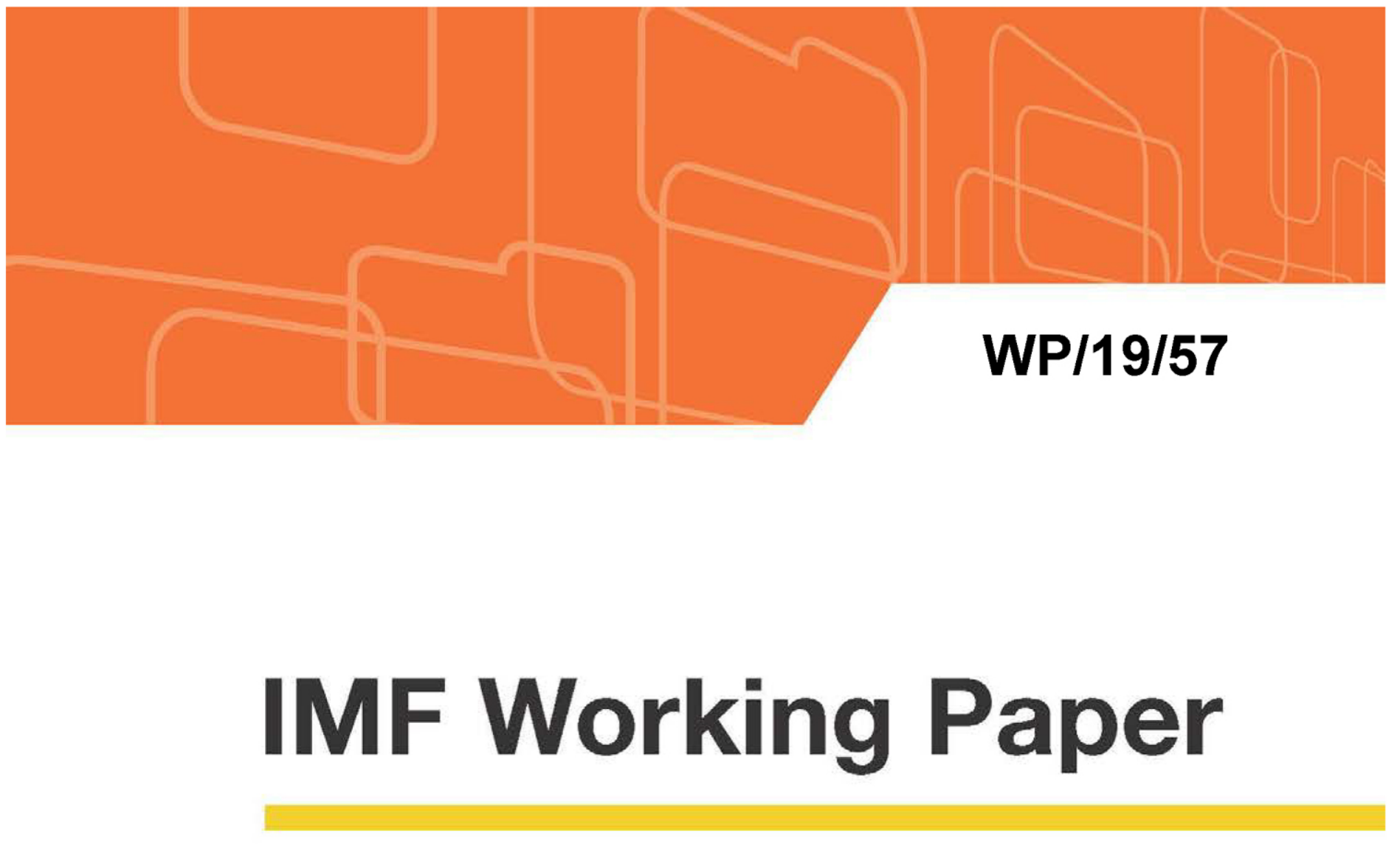

\title{
Two-Sided Market, R\&D and Payments System Evolution
}

by Bin Grace Li, James McAndrews, and Zhu Wang

IMF Working Papers describe research in progress by the author(s) and are published to elicit comments and to encourage debate. The views expressed in IMF Working Papers are those of the author(s) and do not necessarily represent the views of the IMF, its Executive Board, or IMF management.

$$
\text { I N T E R N A T I O N A L M O N E T A R Y F U N D }
$$




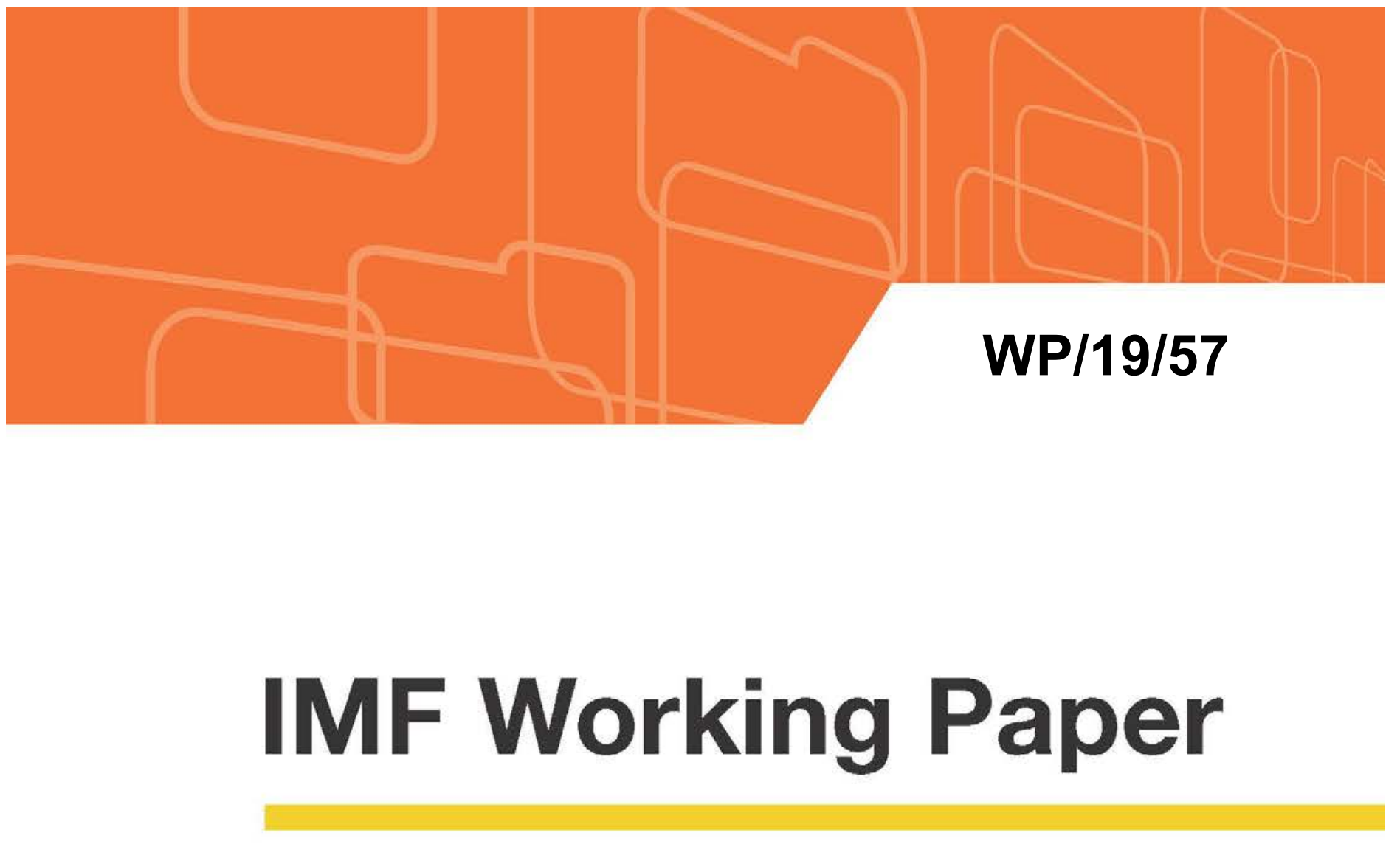

\section{Two-Sided Market, R\&D and Payments System Evolution}

by Bin Grace Li, James McAndrews, and Zhu Wang

IMF Working Papers describe research in progress by the author(s) and are published to elicit comments and to encourage debate. The views expressed in IMF Working Papers are those of the author(s) and do not necessarily represent the views of the IMF, its Executive Board, or IMF management.

$$
\text { I N T E R N A T I O N A L M O N E T A R Y F U N D }
$$




\title{
IMF Working Paper
}

Fiscal Affairs Department

\author{
Two-Sided Market, R\&D and Payments System Evolution* \\ Prepared by Bin Grace Li, James McAndrews, and Zhu Wang \\ Authorized for distribution by Era Dabla-Norris
}

March 2019

\begin{abstract}
IMF Working Papers describe research in progress by the author(s) and are published to elicit comments and to encourage debate. The views expressed in IMF Working Papers are those of the author(s) and do not necessarily represent the views of the IMF, its Executive Board, or IMF management.
\end{abstract}

\begin{abstract}
It takes many years for more efficient electronic payments to be widely used, and the fees that merchants (consumers) pay for using those services are increasing (decreasing) over time. We address these puzzles by studying payments system evolution with a dynamic model in a twosided market setting. We calibrate the model to the U.S. payment card data, and conduct welfare and policy analysis. Our analysis shows that the market power of electronic payment networks plays important roles in explaining the slow adoption and asymmetric price changes, and the welfare impact of regulations may vary significantly through the endogenous $R \& D$ channel.
\end{abstract}

JEL Classification Numbers: E4, G2, O3

Keywords: R\&D, Technology Adoption, Two-Sided Market

Author's E-Mail Address: bli2@imf.org, jamesjmcandrews@gmail.com zhu.wang@rich.frb.org

\footnotetext{
* We thank Boyan Jovanovic and Ricardo Reis for insightful comments that greatly improved the paper. We also thank Jesus Fernandez-Villaverde, Fumiko Hayashi, Chang-Tai Hsieh, Esteban Rossi-Hansberg for helpful comments. The views expressed herein are solely those of the authors and do not necessarily reflect the views of the International Monetary Fund, the Federal Reserve Bank of Richmond or the Federal Reserve System.
} 
1. Introduction

2. The Model

2.1. A Cash Economy__ 29

2.2. Introducing the Payment Card ___ 11

3. Market Equilibrium

3.1. Within-Period Analysis

3.2. Dynamic Analysis

4. Model Calibration $\underline{19}$

4.1. Functional Forms $\underline{20}$

4.2. Model Characterization

4.3. Calibration Results $\underline{21}$

5. Welfare and Policy Analysis $\underline{27}$

5.1. Payment Card and Welfare Improvement $\underline{28}$

5.2. Ramsey Social Planner

5.3. Policy Experiments

6. Conclusion

References $\underline{38}$

Appendix 40 


\section{Introduction}

The payments system is a vital component of the overall economy and its scale is enormous. It is estimated that U.S. consumers made 158 billion purchases worth about $\$ 8.3$ trillion in 2011, not counting payments made by businesses or governments. ${ }^{1}$ The past several decades also have witnessed significant changes in payment technology, particularly the migration from paper to electronic payments. As shown in Fig. 1, the share of card relative to cash payments increases steadily over time, and so does the share of the broadly measured electronic payments relative to paper payments. $^{2}$

In some ways these developments are puzzling. One key question, for example, is why it has taken so long for electronic payments to replace paper payments. For several decades, experts on payments systems have forecast the imminent arrival of a completely electronic, paperless payments system. While the direction of development seems quite clear, the pace has been slow. Most electronic payments that we are familiar with today were introduced decades ago, for example, credit cards in 1950s, ACH in 1970s, and debit cards in 1980s. However, even until the 2000s, their combined market share was just around 50-60 percent (see Fig. 1). The slow transition is also happening to some more recent payment innovations, such as the mobile payments.

Also, there have been controversies regarding competitive efficiency of electronic payments systems, particularly for card-based payments. Merchants claim that payment card networks (e.g., Visa and MasterCard) and their issuing banks have used market power to drive up the fees that merchants pay for accepting credit and debit card payments (the so-called interchange fees, shown in Fig. 2). ${ }^{3}$ This is in sharp contrast to the continuing

\footnotetext{
${ }^{1}$ Data source: Nilson Report \#1008, December 2012.

${ }^{2}$ Data source: Nilson Report, various issues. Card payments include credit and debit card transactions. Broaderly measured electronic payments include card payments plus $\mathrm{ACH}$ and remote payments. $\mathrm{ACH}$ stands for Automated Clearing House, which is an electronic interbank payments system used for small and recurring payments. Remote payments refer to payments made via a phone or computer, and include check conversions at the point of sale and utility payments made at ATMs, self-service kiosks, and clerkassisted machines at supermarkets. Paper payments include cash and check payments.

${ }^{3}$ The fees that merchants pay to accept payment cards are called merchant discount rates. A major component of the merchant discount rates is interchange fees, which are set by card networks and paid by merchants to card issuers through merchant acquirers. In the U.S. and many other countries, the increasing interchange fees have driven up merchants' costs of accepting cards. Figure 2 plots the interchange fee for a $\$ 50$ non-supermarket transaction for Visa and MasterCard credit cards as well as four largest PIN debit card networks in the United States from 1997-2008. Data source: American Banker (various issues).
} 


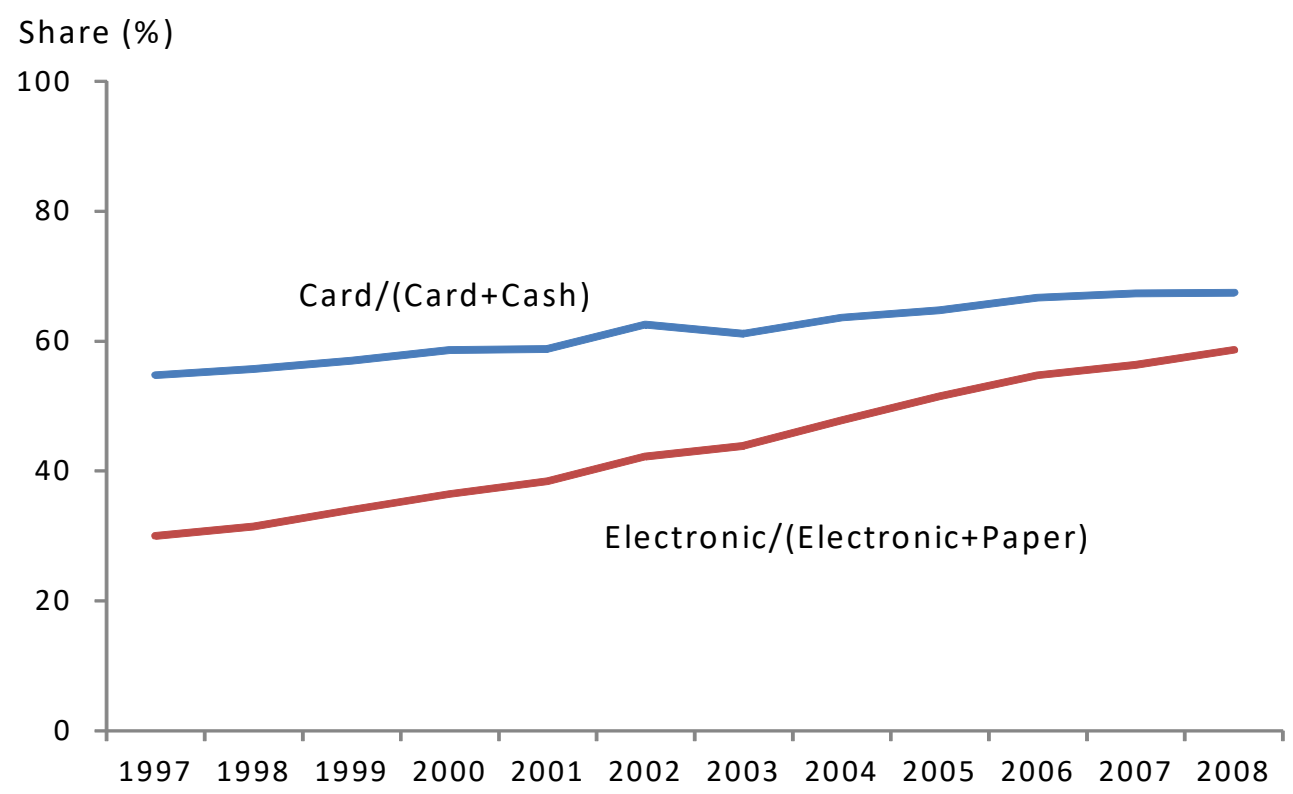

Figure 1: Evolution of Payment Forms

technological progress and declining costs in the payment card industry. In recent years, merchant dissatisfaction with the interchange fees has resulted in major regulations and spectacular antitrust litigations. ${ }^{4}$

To address these controversies, we develop a unified framework for understanding payments system evolution. In recent years, a growing literature on payments economics has tried to explore related issues. On the one hand, some researchers take the moneytheoretical approach and use information economics and mechanism design to characterize alternative payments systems (e.g., Kiyotaki and Wright 1989, Lagos and Wright 2005). ${ }^{5}$ These theories shed light on how payments arrangements overcome frictions of exchange (e.g., limited information or limited enforcement), but they do not directly explain the slow adoption of electronic payments systems. Moreover, those theories often assume that

\footnotetext{
${ }^{4}$ For example, the Congress passed the Durbin Amendment as a provision of the Dodd-Frank Act in July 2010, which directs the Federal Reserve Board to regulate U.S. debit card interchange fees. Subsequently, the Federal Reserve Board implements Regulation II that caps debit card interchange fees at about half of the pre-regulation level. Recently, Visa, MasterCard and their major issuers reached a $\$ 6.2$ billion settlement agreement in September 2018 with U.S. retailers in a lawsuit over credit and debit card interchange fees. The settlement, pending on court approval, aims at ending more than 50 lawsuits that merchants filed since 2005, and would be so far the largest private antitrust settlement in U.S. history.

${ }^{5}$ See Kahn and Roberds (2009), Nosal and Rocheteau (2011) for reviews of recent literature.
} 


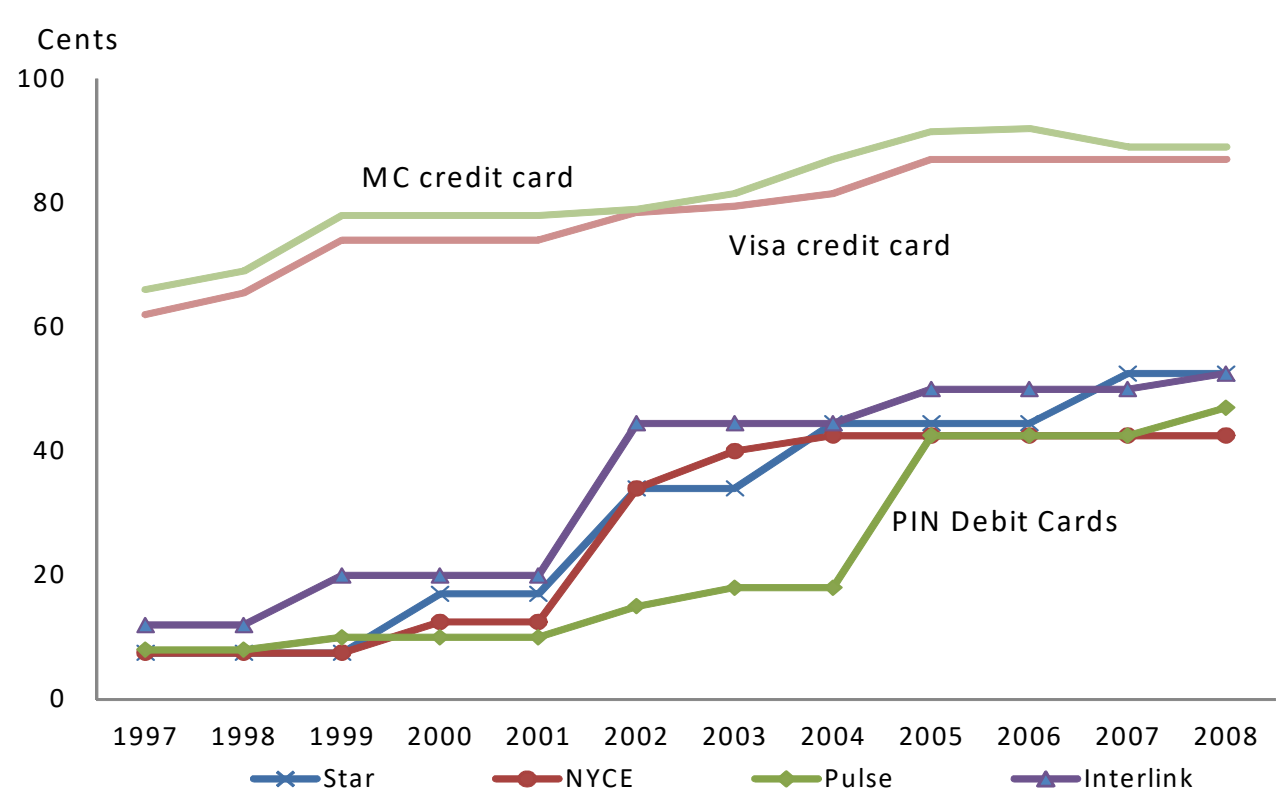

Figure 2: Interchange Fees for a $\$ 50$ Transaction in the U.S.

payment systems are operated by a benevolent planner or by a club of participants, so they do not address the competitive efficiency issues.

On the other hand, some other researchers focus on the industrial organization and pricing issues of payments systems. ${ }^{6}$ Particularly, Rochet and Tirole $(2002,2011)$ argue that the high interchange fees reflect a fundamental failure of the Coase Theorem to hold in the two-sided payment card market (where merchants and consumers are the two sides of card users). While this literature provides important insights into how payment markets function, it has some limitations. For instance, those theories focus on usage externalities of payment means but usually ignore payments adoption decisions and endogenous technological progress. Also, the literature typically imposes an ad hoc distribution of "convenience benefits" from using a particular means of payment and assumes consumers have a fixed demand for goods invariant to their payment choices. Under those assumptions, the adoption and usage patterns of electronic payments are not fully explained, and the welfare analysis is restricted.

In this paper, we provide a new analysis on payments system evolution and the accompanying competitive efficiency issues. Our theory lays out a two-sided market environment

\footnotetext{
${ }^{6}$ See Rysman and Wright (2013) for a review of recent literature.
} 
where consumers of heterogenous income and merchants of heterogenous size make payment choices under network externalities. This setting is embedded in a fully dynamic model, in which a monopoly electronic payment network sets usage fees and conducts R\&D to lower costs. We calibrate the model to match the U.S. payment card pricing, adoption and usage data, and conduct welfare and policy analysis.

Our theory has several novelties. First, we model payment adoption decisions under the natural assumption that adopting a payment innovation requires merchants and consumers each to pay a fixed cost, which allows them to potentially benefit from lower marginal cost of making payments. Second, we introduce heterogeneous income (size) among consumers (merchants) to explain their reliance on alternative payment technologies. Finally, we set aside the typical assumption of inelastic demand for final goods by consumers.

Our approach yields clear implications on the adoption and usage pattern of payment innovations. Consider the introduction of payment cards with a high fixed but low marginal cost of use, as compared with cash. More affluent consumers, with higher levels of consumption and purchases, would be more willing to adopt cards than less affluent consumers. Similarly, larger merchants, or those who sell higher-valued goods, would be more likely to accept cards than other merchants. Over time, as the card network conducts R\&D to continue lowering card service costs, payment cards penetrate into segments of lower-income consumers and smaller merchants. These predictions are consistent with the empirical evidence (see Figs. A1(a)-(c) in the Appendix), but the literature that assumes an unspecified "convenience benefit" of using payments cards does not yield such straightforward empirical implications.

It has previously been pointed out (e.g., Wright, 2003) that a merchant serving both cash and card consumers would be competed out of business in a competitive environment. However, we find that in the presence of a fixed adoption cost, large merchants who serve both cash and card customers do survive the threat of entry from specialized merchants. Indeed, our equilibrium is characterized by three categories of merchants based on their size: Large merchants accept both cash and cards, and set a price that is lower than cashonly merchants. They attract both cash users and card users. Medium-size merchants are specialized. Some of them accept only cash. The others accept both cash and cards, 
but set a price that is higher than the competing cash-only merchants. They attract only card users, because cards are cost-saving to them overall. Finally, small merchants are all cash-only merchants. These predictions are consistent with what we observe in reality, but are not implied by existing theories.

Our analysis shows that the market power of electronic payment networks plays important roles in explaining the slow adoption of electronic payments. To provide a contrast, we find that a Ramsey social planner who aims to maximize consumer and social welfare would set lower usage fees and conduct more $R \& D$, thus achieving a higher adoption and usage of electronic payments. Our analysis also provides a new explanation for high merchant fees observed in the card payment systems. Imposing a high fee to the merchant side allows a card network to inflate retail prices and extract more rents produced by replacing costly cash payments. According to our model, the card network tends to raise merchant fees but reduce consumer fees as card service costs decline over time, a pattern consistent with the data yet unexplained by prior literature. We find that cash users are disadvantaged by the high merchant fee. However, this is not because they have to subsidize card users as suggested by previous theories (in our model, at merchants where both cash and card are used, cash users are subsidized by card users who by their use of a more efficient payment means, contribute to a lower overall costs of payment at the merchant). Instead, the card network sets the merchant fee too high so that fewer stores serve both card and cash users, hence fewer cash users get subsidized by card users.

Our paper also extends the existing literature by offering additional policy insights. Based on the calibrated model, we compare two regulatory approaches: One requires the card network to price at marginal cost, and the other caps the merchant fee. We find that while marginal-cost pricing could maximize consumer welfare in a static setting, it shuts off the card network's R\&D and may reduce social welfare in a dynamic setting. In comparison, the merchant fee cap regulation improves consumer welfare but without causing much dynamic inefficiency.

The paper is organized as follows. Section 2 lays out the model setup with two competing payment means, "cash" versus "card." Section 3 characterizes the model equilibrium and dynamic path. Section 4 calibrates the model to the U.S. payment card data. Section 5 conducts welfare and policy analysis. Finally, Section 6 concludes. 


\section{The Model}

Our model studies pricing, adoption and usage of payment devices. We first lay out a market environment in which only a paper device, "cash," is in use. We then introduce an electronic device, the "card." In our analysis, certain market conditions, such as the variety of goods and the consumer income distribution, are exogenously given. ${ }^{7}$

\subsection{A Cash Economy}

The market is composed of a continuous distribution of merchants of measure unity. Each merchant sells a distinct consumption good characterized by two parameters: consumer preference $\alpha$ and unit cost $\mu$. The unit cost $\mu$ is measured in terms of a numeraire good called dollar. For ease of notation, we assume goods with the same value of $\alpha$ share the same value of unit cost denoted as $\mu_{\alpha}{ }^{8}$

Cash is the sole payment device in the economy. Merchants incur a transaction $\operatorname{cost} \tau_{m}$ per dollar for accepting cash, which includes handling, safekeeping and fraud expenses. ${ }^{9}$ The market is contestable so merchants earn zero profits. As a result, the cash price for a good $\alpha$ is determined as $p_{\alpha, h}$, where

$$
p_{\alpha, h}=\frac{\mu_{\alpha}}{1-\tau_{m}}
$$

Each period, a consumer receives her income $I$ in terms of the numeraire good (which could be interpreted as the payoff to her endowment of effective labor). ${ }^{10}$ The consumer, indexed by her income $I$, purchases a variety of goods from merchants, each of which associates with a preference parameter $\alpha$, where $\alpha \in(0, \bar{\alpha})$. The consumer has a Cobb-

\footnotetext{
${ }^{7}$ The static environment of the model follows closely McAndrews and Wang (2012), upon which we construct a fully dynamic model and conduct quantitative analysis.

${ }^{8}$ This is an innocuous assumption. As will become clear, the cost parameter $\mu_{\alpha}$ plays no role in our analysis except scaling the level of utility.

${ }^{9}$ The transaction costs, $\tau_{m}$ and $\tau_{c}$, may include any fees that merchants and consumers need to pay for using paper payments. In our analysis, we abstract from the issue that the government may subsidize paper payments (e.g., providing paper payment services below cost), in which case $\tau_{m}$ and $\tau_{c}$ may not fully reflect the social cost of using paper payments. However, considering government subsidies to paper payments would make our welfare findings even stronger because it provides an additional reason why electronic payments are being underused.

${ }^{10}$ For simplicity, we assume there is no intertemporal saving technology, so income is fully consumed each period.
} 
Douglass utility $U_{I}$, and her consumption of each good $\alpha$ is denoted as $x_{\alpha, I}$. Let $G(\alpha)$ be the cumulative distribution function of $\alpha$ and denote $E(\alpha)=\int_{0}^{\bar{\alpha}} \alpha d G(\alpha)$, so

$$
\ln U_{I}=\int_{0}^{\bar{\alpha}} \frac{\alpha}{E(\alpha)} \ln x_{\alpha, I} d G(\alpha),
$$

where $\int_{0}^{\bar{\alpha}} \frac{\alpha}{E(\alpha)} d G(\alpha)=1$. The consumer's budget constraint is

$$
\int_{0}^{\bar{\alpha}}\left(1+\tau_{c}\right) p_{\alpha, h} x_{\alpha, I} d G(\alpha)=I,
$$

where $\tau_{c}$ is the consumer's transaction cost of using cash. Maximizing the utility (2) subject to the constraint (3) yields consumer I's demand for each good $\alpha$ :

$$
x_{\alpha, I}^{*}=\frac{\alpha I}{E(\alpha)\left(1+\tau_{c}\right) p_{\alpha, h}} .
$$

As a result, consumer $I$ enjoys the utility level $U_{I, h}$ such that

$$
\ln U_{I, h}=\ln I+\int_{0}^{\bar{\alpha}} \frac{\alpha}{E(\alpha)} \ln \frac{\alpha}{E(\alpha)\left(1+\tau_{c}\right) p_{\alpha, h}} d G(\alpha)
$$

This implies that a consumer's utility is proportional to her income,

$$
U_{I, h}=I \overline{U_{h}}
$$

where $\overline{U_{h}}=\exp \left\{\int_{0}^{\bar{\alpha}} \frac{\alpha}{E(\alpha)} \ln \frac{\alpha}{E(\alpha)\left(1+\tau_{c}\right) p_{\alpha, h}} d G(\alpha)\right\}$ is the utility associated with one dollar of income.

Income $I$ varies across consumers and is distributed according to a cumulative distribution function $F(I)$ on the support $(0, \bar{I})$. We denote $E(I)=\int_{0}^{\bar{I}} I d F(I)$ as the mean income and normalize the measure of consumers to be unity. At equilibrium, a merchant's sale of good $\alpha$ equals its total demand:

$$
x_{\alpha}=\int_{0}^{\bar{I}} x_{\alpha, I} d F(I)=\frac{\alpha E(I)}{E(\alpha)\left(1+\tau_{c}\right) p_{\alpha, h}} .
$$

It follows from Eq (7) that the size of a merchant, measured by the value of sales $p_{\alpha, h} x_{\alpha}$, increases with the preference index $\alpha$ of the good that the merchant sells. 


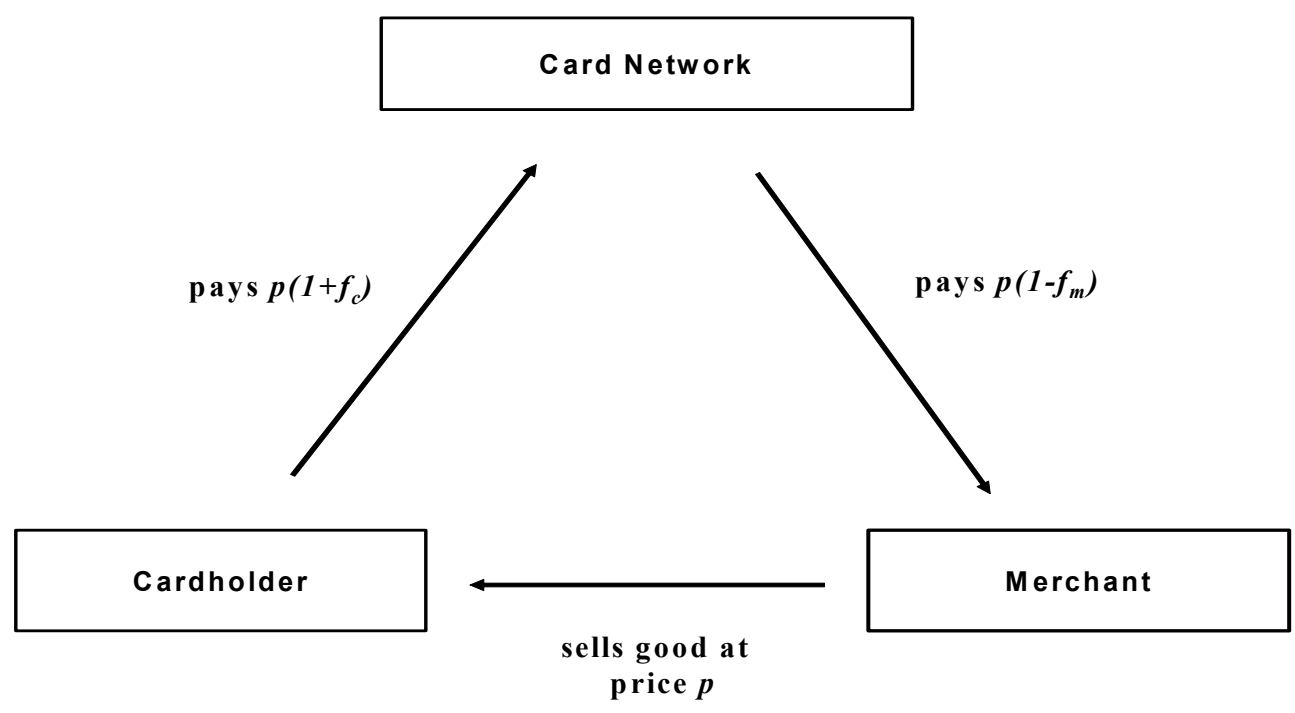

Figure 3: Payment Card System

\subsection{Introducing the Payment Card}

We now introduce an electronic payment innovation, referred to as a payment card. The card service is provided by a monopoly network. The costs of providing the card service to merchants and consumers are $d_{m}$ and $d_{c}$ per-dollar transaction respectively, and we denote the sum $d=d_{m}+d_{c}$. It will become clear that in our two-sided market setting, only the sum $d$ (but not its composition, $d_{m}$ and $d_{c}$ ) matters for the analysis. In return, the card service provider charges merchants and consumers a percentage fee $f_{m}$ and $f_{c}$, respectively. ${ }^{11}$ Figure 3 describes the transaction flow in the card system in which consumers use a payment card to pay merchants. Merchants submit charges to the card network which then bills consumers. ${ }^{12}$

We adopt the convention that the transaction costs for merchants and consumers to

\footnotetext{
${ }^{11}$ Assuming payment cards charge percentage fees is consistent with reality. In most countries, credit cards charge fees proportional to the transaction value. In the U.S., most debit cards also charge percentage fees (Shy and Wang, 2011).

${ }^{12}$ For simplicity, we model a "three-party" system where the payment card network serves consumers and merchants directly, but our analysis can equally apply to a "four-party" system where the card network serves consumers and merchants indirectly through card issuers and merchant acquirers. It is typically considered in the literature that merchant acquiers are competitive and the card network maximizes the joint profits of member issuers, so we can simply reinterpret the card network in our model to be the association of member issuers in a "four-party" system.
} 
use payment cards are normalized at 0. Therefore, the avoided costs of handling cash, $\tau_{m}$ and $\tau_{c}$, are the convenience benefits of card payments to merchants and consumers, respectively. For the card being a more efficient payment means, we impose the condition:

$$
\tau_{m}+\tau_{c}>d
$$

In order to adopt the payment card, a merchant and a consumer each incur a fixed cost $K_{m}$ and $K_{c}$ every period, respectively. The fixed costs may arise for technological or institutional reasons. For example, a merchant may incur a fixed cost renting cardprocessing equipment and/or training employees, while a consumer may incur a fixed cost maintaining her bank balance or credit score. Therefore, in deciding whether to accept or hold the payment card, merchants and consumers need to weigh the benefit of avoiding handling cash against their card adoption costs and usage fees. For merchants who decide to accept payment cards, they still have to accept cash and charge a single price to card and cash customers. ${ }^{13}$

To study the industry evolution, we proceed in two steps with the following analysis.

(i) Within-Period Analysis. At a point of time, with the card service cost $d$ given, we solve for a subgame perfect Nash equilibrium of the following three-stage game:

Stage I. The payment card network sets the card fees $f_{m}$ and $f_{c}$.

Stage II. After observing $f_{m}$ and $f_{c}$, merchants make card acceptance decisions and post retail prices for the period. Meanwhile, consumers decide whether to hold cards.

Stage III. Consumers then decide whether to purchase, which merchants to purchase from, and what payment device to use.

In making the decisions, consumers and merchants each maximize their utility or profits, and the card network sets card fees to maximize profit.

\footnotetext{
${ }^{13}$ This is referred to as "price coherence" in the literature, and has been commonly seen in reality. Price coherence may result from network rules or state regulation (e.g., In the U.S., card network rules and some state laws explicitly prohibit surcharging on payment cards), or from high transaction costs for merchants to price discriminate based on payment means (e.g., even if surcharging payment cards is allowed, few merchants would choose to do so).
} 
(ii) Dynamic Analysis. The industry evolves over time. To study the industry evolution, we assume time is discrete and the payment card is introduced at time 0 . We add back the time subscripts to variables. On the one hand, the mean consumer income $E\left(I_{t}\right)$ may grow exogenously, together with the changes of card adoption costs $K_{m, t}$ and $K_{c, t}$. On the other hand, the card network can make endogenous R\&D investment $R_{t}$ (in units of the numeraire good) to reduce the card service cost next period such that

$$
d_{t+1}=\Gamma\left(d_{t}, R_{t}\right)
$$

where $\partial \Gamma / \partial d_{t}>0$ and $\partial \Gamma / \partial R_{t}<0$. Given the initial value of $d_{0}$ and the laws of motion for $E\left(I_{t}\right), K_{m, t}$ and $K_{c, t}$, the card network chooses a sequence of card fees $\left(f_{m, t}, f_{c, t}\right)$ and $\mathrm{R} \& \mathrm{D}$ investment $R_{t}$ to maximize the present value of profits.

\section{Market Equilibrium}

In this section, we study the market equilibrium under the profit-maximizing network. We first study the industry equilibrium within a period, for which the industry has given values of $d, E(I), K_{m}$ and $K_{c}$. We then embed that in a fully dynamic setting to study the industry evolution.

\subsection{Within-Period Analysis}

At a point of time, the industry has given values of $d, E(I), K_{m}$ and $K_{c}$. The market equilibrium can be solved backward for the three-stage game. In Stages II and III, given card fees $f_{m}$ and $f_{c}$ set by the card network, merchants and consumers each decide their own card adoption and usage, taking others' decisions as given. In Stage I, anticipating consumers' and merchants' responses, the card network decides the profit-maximizing card fees.

Note that the interactions between the two sides of the market can easily yield multiple equilibria. For example, an equilibrium may exist at which neither merchants nor consumers adopt cards. In the following analysis, we will focus on an equilibrium with positive card adoption and usage. We show that there exist threshold values of merchant 
size and consumer income, above which merchants and consumers accept and hold cards. We will first construct such an equilibrium and then characterize its properties.

\subsubsection{Merchants' Choices}

Merchants take card fees as given and expect that consumers $I \geq I_{0}$ would hold cards when making their card acceptance decision. Recall that the index $\alpha$ indicates merchant size. It can be shown that there exist two threshold values $\alpha_{1}$ and $\alpha_{0}$, where $\alpha_{1}>\alpha_{0}$, so that merchants fall into three categories: (1) Large merchants $\left(\alpha \geq \alpha_{1}\right)$ accept both cash and cards, and charge price $p_{\alpha, d} \leq p_{\alpha, h}$ so they are patronized by both cash and card customers. (2) Intermediate merchants $\left(\alpha_{0} \leq \alpha<\alpha_{1}\right)$ specialize. Some accept both cash and cards, and charge $p_{\alpha, d}$ where $\frac{1+\tau_{c}}{1+f_{c}} p_{\alpha, h} \geq p_{\alpha, d}>p_{\alpha, h}$, so they are patronized only by card customers. The others do not accept cards and charge $p_{\alpha, h}$, so they only serve cash customers. (3) Small merchants $\left(\alpha<\alpha_{0}\right)$ only accept cash, so all customers make purchases there using cash regardless of whether they have adopted a card.

As we will show next, the thresholds $\alpha_{1}$ and $\alpha_{0}$ are endogenously determined under

card fees $f_{m}$ and $f_{c}$. Note that because merchants who accept payment cards still have to accept cash and charge a single price to card and cash users, the consumer card fee has to be below the consumer cost of handling cash, i.e., $f_{c} \leq \tau_{c}$. This condition can be thought as a card pricing constraint to provide consumers "incentive at the counter" to use payment cards. As we show in the following analysis, card fees also need to satisfy additional pricing constraints which make card-accepting stores attractive to consumers, in other words, providing consumers "incentive at the door."

Large Merchants: $\alpha \geq \alpha_{1}$. Merchants in this category charge $p_{\alpha, d} \leq p_{\alpha, h}$ and receive revenues from both card customers $\left(I \geq I_{0}\right)$ and cash customers $\left(I<I_{0}\right)$ :

$$
p_{\alpha, d} x_{\alpha, d}^{c a r d}=\frac{\alpha\left[E_{I \geq I_{0}}\left(I-K_{c}\right)\right]}{E(\alpha)\left(1+f_{c}\right)}, \quad p_{\alpha, d} x_{\alpha, d}^{c a s h}=\frac{\alpha\left[E_{I<I_{0}}(I)\right]}{E(\alpha)\left(1+\tau_{c}\right)},
$$

where $E_{I \geq I_{0}}(I) \equiv \int_{I_{0}}^{\bar{I}} I d F(I)$.

Because merchants need to post their prices and cannot make changes in the same period, they each set a lowest possible price to prevent being undercut by potential en- 
trants. This contestable market assumption leads to zero profit so that a merchant's total revenue equals total cost,

$$
\left(1-f_{m}\right) p_{\alpha, d} x_{\alpha, d}^{c a r d}+\left(1-\tau_{m}\right) p_{\alpha, d} x_{\alpha, d}^{c a s h}=\mu_{\alpha} x_{\alpha, d}^{c a r d}+\mu_{\alpha} x_{\alpha, d}^{c a s h}+K_{m}
$$

Equations (9) and (10) pin down the price $p_{\alpha, d}$ :

$$
p_{\alpha, d}=\frac{\mu_{\alpha} \frac{\alpha\left[E_{I \geq I_{0}}\left(I-K_{c}\right)\right]}{\left(1+f_{c}\right)}+\mu_{\alpha} \frac{\alpha\left[E_{\left.I<I_{0}(I)\right]}\right.}{\left(1+\tau_{c}\right)}}{\left(1-f_{m}\right) \frac{\alpha\left[E_{I \geq I_{0}}\left(I-K_{c}\right)\right]}{1+f_{c}}+\left(1-\tau_{m}\right) \frac{\alpha\left[E_{I<I_{0}}(I)\right]}{1+\tau_{c}}-K_{m} E(\alpha)} .
$$

Recall Eq. (1) that $p_{\alpha, h}=\mu_{\alpha} /\left(1-\tau_{m}\right)$. Hence, $p_{\alpha, d} \leq p_{\alpha, h}$ implies that there exists a threshold

$$
\alpha_{1}=\frac{K_{m} E(\alpha)}{\left[E_{I \geq I_{0}}\left(I-K_{c}\right)\right]\left(\frac{1-f_{m}}{1+f_{c}}-\frac{1-\tau_{m}}{1+f_{c}}\right)} \quad \text { if } \quad f_{m} \leq \tau_{m},
$$

so that merchants whose size $\alpha \geq \alpha_{1}$ fall into this category. Note Eq. (12) suggests that no merchant would belong to this category if $f_{m}>\tau_{m}$, because the prices they offer would not attract cash users.

Medium-size Merchants: $\alpha_{0} \leq \alpha<\alpha_{1}$. Merchants in this category specialize. For each good, there are two merchants. One accepts both cash and card, and charges $p_{\alpha, d}$ where $\frac{1+\tau_{c}}{1+f_{c}} p_{\alpha, h} \geq p_{\alpha, d}>p_{\alpha, h}$, so it is patronized only by card customers $\left(I \geq I_{0}\right) .{ }^{14}$ The other does not accept cards and charges $p_{\alpha, h}$, so it only serves cash customers $\left(I<I_{0}\right)$.

A card-accepting merchant in this category receives revenues only from card customers and earns zero profit, which implies

$$
p_{\alpha, d}=\frac{\mu_{\alpha} \frac{\alpha\left[E_{I \geq I_{0}}\left(I-K_{c}\right)\right]}{\left(1+f_{c}\right)}}{\left(1-f_{m}\right) \frac{\alpha\left[E_{I \geq I_{0}}\left(I-K_{c}\right)\right]}{1+f_{c}}-K_{m} E(\alpha)} .
$$

Therefore, $\frac{1+\tau_{c}}{1+f_{c}} p_{\alpha, h} \geq p_{\alpha, d}>p_{\alpha, h}$ implies that merchants $\alpha_{0} \leq \alpha<\alpha_{1}$ are in this group, where $\alpha_{1}$ is given in Eq. (12) and $\alpha_{0}$ is determined by

$$
\alpha_{0}=\frac{K_{m} E(\alpha)}{\left[E_{I \geq I_{0}}\left(I-K_{c}\right)\right]\left(\frac{1-f_{m}}{1+f_{c}}-\frac{1-\tau_{m}}{1+\tau_{c}}\right)} .
$$

\footnotetext{
${ }^{14}$ Because $p_{\alpha, d}>p_{\alpha, h}$, the merchant would not attract cash customers. But given $\left(1+f_{c}\right) p_{\alpha, d} \leq$ $\left(1+\tau_{c}\right) p_{\alpha, h}$, the merchant would attract card users because cards are cost-saving to them overall.
} 
Equations (12) and (14) suggest that $\frac{1-f_{m}}{1+f_{c}} \geq \frac{1-\tau_{m}}{1+\tau_{c}}$ has to hold for any merchants in the market ever to accept cards. In fact, if $\frac{1-f_{m}}{1+f_{c}}<\frac{1-\tau_{m}}{1+\tau_{c}}$, there would be no merchant in either category $(1)$ or $(2) \cdot{ }^{15}$

Small Merchants: $\alpha<\alpha_{0}$. Given $\frac{1-f_{m}}{1+f_{c}} \geq \frac{1-\tau_{m}}{1+\tau_{c}}$, small merchants $\alpha<\alpha_{0}$ are in the third category. Due to small transaction values, these merchants cannot afford paying the fixed adoption cost to accept cards. Otherwise, it would result in $p_{\alpha, d}>\frac{1+\tau_{c}}{1+f_{c}} p_{\alpha, h}$. Therefore, they only accept cash and all consumers, regardless of holding a card or not, make purchases there using cash.

\subsubsection{Consumers' Choices}

An individual consumer takes market prices, card fees and merchants' card acceptance as given and decides whether to hold a payment card or not. Recall that merchants in the market fall into three categories according to their sizes. A consumer $I$, if not adopting the card, may use cash and derive utility $U_{I, d}^{h}$ from shopping at card-acceptance stores in category (1) and at cash-only stores in categories (2) and (3). Accordingly,

$\ln U_{I, d}^{h}=\int_{0}^{\min \left(\alpha_{1}, \bar{\alpha}\right)} \frac{\alpha}{E(\alpha)} \ln \frac{\alpha I}{\left(1+\tau_{c}\right) p_{\alpha, h} E(\alpha)} d G(\alpha)+\int_{\min \left(\alpha_{1}, \bar{\alpha}\right)}^{\bar{\alpha}} \frac{\alpha}{E(\alpha)} \ln \frac{\alpha I}{\left(1+\tau_{c}\right) p_{\alpha, d} E(\alpha)} d G(\alpha)$.

In contrast, if she holds a payment card, she can use the card to shop at card-accepting stores in categories (1) and (2), though she still needs to use cash at stores in category (3). As a result, she derives utility $U_{I, d}^{d}$ so that

$$
\ln U_{I, d}^{d}=\int_{0}^{\alpha_{0}} \frac{\alpha}{E(\alpha)} \ln \frac{\alpha\left(I-K_{c}\right)}{\left(1+\tau_{c}\right) p_{\alpha, h} E(\alpha)} d G(\alpha)+\int_{\alpha_{0}}^{\bar{\alpha}} \frac{\alpha}{E(\alpha)} \ln \frac{\alpha\left(I-K_{c}\right)}{\left(1+f_{c}\right) p_{\alpha, d} E(\alpha)} d G(\alpha)
$$

Therefore, consumer card adoption requires $\ln U_{I, d}^{d} \geq \ln U_{I, d}^{h}$, which implies

$$
E_{\alpha \geq \alpha_{0}}(\alpha) \ln \left(\frac{1+\tau_{c}}{1+f_{c}}\right) \geq E(\alpha) \ln \left(\frac{I}{I-K_{c}}\right)+\int_{\alpha_{0}}^{\min \left(\alpha_{1}, \bar{\alpha}\right)} \alpha \ln \left(\frac{p_{\alpha, d}}{p_{\alpha, h}}\right) d G(\alpha)
$$

where $E_{\alpha \geq \alpha_{0}}(\alpha) \equiv \int_{\alpha_{0}}^{\bar{\alpha}} \alpha d G(\alpha)$.

\footnotetext{
${ }^{15}$ Because $\tau_{c} \geq f_{c}$ has to hold for any consumers to use cards, $\frac{1-f_{m}}{1+f_{c}}<\frac{1-\tau_{m}}{1+\tau_{c}}$ implies $f_{m}>\tau_{m}$.
} 
Equation (15) suggests that an adopter's income has to satisfy $I \geq I_{0}$ :

$$
I_{0}=\frac{\left(\frac{1+\tau_{c}}{1+f_{c}}\right)^{E_{\alpha \geq \alpha_{0}}(\alpha) / E(\alpha)} K_{c}}{\left(\frac{1+\tau_{c}}{1+f_{c}}\right)^{E_{\alpha \geq \alpha_{0}}(\alpha) / E(\alpha)}-\exp \left(\int_{\alpha_{0}}^{\min \left(\alpha_{1}, \bar{\alpha}\right)} \frac{\alpha}{E(\alpha)} \ln \left(\frac{p_{\alpha, d}}{p_{\alpha, h}}\right) d G(\alpha)\right)}
$$

where

$$
\left(\frac{p_{\alpha, d}}{p_{\alpha, h}}\right)_{\alpha_{0} \leq \alpha<\min \left(\alpha_{1}, \bar{\alpha}\right)}=\frac{\frac{1-\tau_{m}}{1+f_{c}}\left[E_{I \geq I_{0}}\left(I-K_{c}\right)\right]}{\frac{1-f_{m}}{1+f_{c}}\left[E_{I \geq I_{0}}\left(I-K_{c}\right)\right]-\frac{E(\alpha)}{\alpha} K_{m}}
$$

follows Eqs. (1) and (13).

\subsubsection{Two-sided Market Interactions}

As shown above, the interactions between consumer and merchant card adoption are described by the threshold equations (12), (14), (16), and (17).

To simplify the notations, we denote:

$$
Z_{1}=\left(\frac{1-f_{m}}{1+f_{c}}-\frac{1-\tau_{m}}{1+f_{c}}\right), \quad Z_{0}=\left(\frac{1-f_{m}}{1+f_{c}}-\frac{1-\tau_{m}}{1+\tau_{c}}\right)
$$

And we can summarize our findings into the following proposition.

Proposition 1 Given card fees $\left(f_{c}\right.$ and $\left.f_{m}\right)$ that satisfy

$$
\tau_{c} \geq f_{c} \quad \text { and } \quad \frac{1-f_{m}}{1+f_{c}} \geq \frac{1-\tau_{m}}{1+\tau_{c}}
$$

there exist threshold values of merchant size $\left(\alpha_{0}\right.$ and $\left.\alpha_{1}\right)$ and consumer income $\left(I_{0}\right)$, above which merchants and consumers accept and hold cards, where

$$
\begin{gathered}
\alpha_{0}=\frac{K_{m} E(\alpha)}{\left[E_{I \geq I_{0}}\left(I-K_{c}\right)\right] Z_{0}}, \\
\alpha_{1}=\frac{Z_{0}}{Z_{1}} \alpha_{0} \quad \text { if } \quad f_{m} \leq \tau_{m}, \\
I_{0}=\frac{\left(\frac{1+\tau_{c}}{1+f_{c}}\right)^{E_{\alpha \geq \alpha_{0}}(\alpha) / E(\alpha)} K_{c}}{\left(\frac{1+\tau_{c}}{1+f_{c}}\right)^{E_{\alpha \geq \alpha_{0}}(\alpha) / E(\alpha)}-\exp \left(\int_{\alpha_{0}}^{\min \left(\alpha_{1}, \bar{\alpha}\right)} \frac{\alpha}{E(\alpha)} \ln \frac{\left(1-\tau_{m}\right) \alpha}{\left(1-f_{m}\right) \alpha-\left(1+f_{c}\right) \alpha_{0} Z_{0}} d G(\alpha)\right)} .
\end{gathered}
$$




\subsubsection{Within-Period Equilibrium}

The card network, anticipating merchants' and consumers' card adoption and usage decisions in stages II and III, would set card fees $\left(f_{c}, f_{m}\right)$ at Stage I to maximize its profit. Accordingly, the card network solves the following problem:

$$
\begin{gathered}
\pi\left(d ; E(I), K_{m}, K_{c}\right)=\max _{f_{c}, f_{m}} \frac{E_{\alpha \geq \alpha_{0}}(\alpha) E_{I \geq I_{0}}\left(I-K_{c}\right)}{E(\alpha)\left(1+f_{c}\right)}\left(f_{c}+f_{m}-d\right) \\
\text { s.t. } \quad \text { Eqs. }(19),(20),(21),(22) .
\end{gathered}
$$

As shown in (23), the network's profit equals consumers' total spending on cards times its markup. In order to maximize profit, the network internalizes the two-sided market externalities by setting the optimal card fees $\left(f_{c}^{*}, f_{m}^{*}\right)$ which determine the card adoption thresholds for merchants and consumers. Given the optimal card fees $\left(f_{c}^{*}, f_{m}^{*}\right)$, the market achieves a within-period equilibrium, at which the card network maximizes profit, consumers maximize utility, merchants break even, and good and payments markets clear.

\subsection{Dynamic Analysis}

For the dynamic analysis, we add back time subscripts to variables. Over time, the market may evolve due to exogenous changes (e.g., in mean consumer income $E\left(I_{t}\right)$ and card adoption costs $\left.K_{m, t}, K_{c, t}\right)$ and the network's endogenous R\&D investment $R_{t}$. Embedding the within-period equilibrium into the dynamic setting, the value function of the card network is defined as follows:

$$
\begin{gathered}
V\left(d_{t} ; E\left(I_{t}\right), K_{m, t}, K_{c, t}\right)=\max _{R_{t}} \pi\left(d_{t} ; E\left(I_{t}\right), K_{m, t}, K_{c, t}\right)-R_{t} \\
+\beta V\left(d_{t+1} ; E\left(I_{t+1}\right), K_{m, t+1}, K_{c, t+1}\right)
\end{gathered}
$$

where $\pi\left(d_{t} ; E\left(I_{t}\right), K_{m, t}, K_{c, t}\right)$ is the card network's within-period profit, $\beta$ is the discount rate, and $\Gamma$ is the $R \& D$ function. 
To solve the dynamic optimization problem, we can rewrite the constraint (25) as

$$
R_{t}=\Psi\left(d_{t}, d_{t+1}\right)
$$

where $\Psi$ is the inverse function of $\Gamma$. As a result, if the budget constraint (26) is never binding (which is verified in our calibrated model), the problem (24) is equivalent to

$$
\begin{aligned}
V\left(d_{t} ; E\left(I_{t}\right), K_{m, t}, K_{c, t}\right)= & \max _{d_{t+1}} \pi\left(d_{t} ; E\left(I_{t}\right), K_{m, t}, K_{c, t}\right)-\Psi\left(d_{t}, d_{t+1}\right) \\
& +\beta V\left(d_{t+1} ; E\left(I_{t+1}\right), K_{m, t+1}, K_{c, t+1}\right) .
\end{aligned}
$$

As long as the functions $\pi$ and $\Psi$ and the laws of motion for $E\left(I_{t}\right), K_{m, t}$ and $K_{c, t}$ satisfy standard regularity conditions, the optimal solution to (28) can be pinned down by the following first-order and envelope conditions:

$$
\begin{gathered}
\Psi_{2}\left(d_{t}, d_{t+1}\right)=\beta V^{\prime}\left(d_{t+1} ; E\left(I_{t+1}\right), K_{m, t+1}, K_{c, t+1}\right), \\
V^{\prime}\left(d_{t} ; E\left(I_{t}\right), K_{m, t}, K_{c, t}\right)=\pi^{\prime}\left(d_{t} ; E\left(I_{t}\right), K_{m, t}, K_{c, t}\right)-\Psi_{1}\left(d_{t}, d_{t+1}\right) .
\end{gathered}
$$

Combining (29) and (30) yields a second-order difference equation

$$
\Psi_{2}\left(d_{t}, d_{t+1}\right)=\beta\left[\pi^{\prime}\left(d_{t+1} ; E\left(I_{t+1}\right), K_{m, t+1}, K_{c, t+1}\right)-\Psi_{1}\left(d_{t+1}, d_{t+2}\right)\right],
$$

which, together with boundary conditions of $d_{t}$ (i.e., $d_{0}$ is given and $d_{\infty}=0$ ) and the laws of motion for $E\left(I_{t}\right), K_{m, t}$ and $K_{c, t}$, would pin down the dynamic equilibrium path.

\section{Model Calibration}

In this section, we calibrate the model to the U.S. payment card data. We first lay out functional form assumptions and characterize the model properties, and we then choose parameter values to match the model with the U.S. credit and debit card pricing, adoption and usage data. 


\subsection{Functional Forms}

To take our model to data, we make the following functional form assumptions F1-F4.

F1. Merchant size and consumer income follow explicit distributions: $\alpha \in(0,1)$ is uniformly distributed where $G(\alpha)=\alpha$ and $E(\alpha)=1 / 2$; and $I_{t} \in(0, \infty)$ is exponentially distributed where $F\left(I_{t}\right)=1-e^{\left(-\lambda_{t} I_{t}\right)}$ and $E\left(I_{t}\right)=1 / \lambda_{t}{ }^{16}$

F2. The mean consumer income has a constant growth rate $g_{I}$ such that $\lambda_{t+1}=$ $\lambda_{t} /\left(1+g_{I}\right)$.

F3. The card adoption costs are proportional to the mean consumer income: $K_{m, t}=$ $k_{m} E\left(I_{t}\right)=k_{m} / \lambda_{t}$ and $K_{c, t}=k_{c} E\left(I_{t}\right)=k_{c} / \lambda_{t}$, where $k_{m}$ and $k_{c}$ are fixed parameters.

F4. The R\&D function $\Gamma$ takes the following form:

$$
\frac{1}{d_{t+1}}-\frac{1}{d_{t}}=\left(\frac{R_{t} \lambda_{t}}{\phi}\right)^{\gamma} d_{t}^{-\gamma-1} \text { with } 1>\gamma>0
$$

where R\&D investment (scaled by income), $R_{t} / E\left(I_{t}\right)=R_{t} \lambda_{t}$, enters the function and $\phi$ is a fixed parameter measuring the efficiency of R\&D.

The functional form assumptions are made mainly for tractability. Note that one assumption in F1 that merchant size $\alpha$ follows a uniform distribution is inessential, and our model findings continue to hold for positively skewed distributions. ${ }^{17}$ Another assumption that consumer income $I_{t}$ follows an exponential distribution matches well the U.S. data, as shown by Dragulescu and Yakovenkoa (2001). Moreover, the exponential distribution has a constant Gini coefficient at 0.5 (which also agrees well with the U.S. data) ${ }^{18}$ which allows our analysis to focus on the change in the mean income while holding the income inequality fixed.

F2-F3 are simplifying assumptions that reduce free parameters of the model so that we can draw sharp results for the dynamic analysis. Particularly, by tying card adoption costs $K_{m, t}$ and $K_{c, t}$ to the mean consumer income $1 / \lambda_{t}$, the exogenous growth of income would only affect card transaction values but not the adoption thresholds, with the latter being

\footnotetext{
${ }^{16}$ Note that $E_{\alpha \geq \alpha_{0}}(\alpha)=\frac{1-\alpha_{0}^{2}}{2}$ and $E_{I_{t} \geq I_{0}}\left(I_{t}-K_{c, t}\right)=e^{-\lambda_{t} I_{0}}\left(\frac{1}{\lambda_{t}}+I_{0}-K_{c, t}\right)$.

${ }^{17}$ As a robustness check, we considered an alternative assumption that merchant size $\alpha$ follows an exponential distribution and all the results are very similar.

${ }^{18}$ E.g., Dragulescu and Yakovenkoa (2001) report that the Gini coeffcient for U.S. personal income was between 0.47 and 0.56 from 1979-1997.
} 
fully driven by the endogenous decline in card service costs $d_{t}$. F4 models the decline in card service costs $d_{t}$ as a result of R\&D, and because R\&D may entail opportunity costs of labor hours, we scale it by the mean consumer income (i.e., $R_{t} / E\left(I_{t}\right)=R_{t} \lambda_{t}$ ). As will become clear, the R\&D function form (31) allows us to derive a balanced growth path in the dynamic analysis.

\subsection{Model Characterization}

Before we take the model to data, we characterize some important properties of the model equilibrium given the functional form assumptions we made.

\subsubsection{Within-Period Equilibrium}

We start with the within-period equilibrium. First, given adoption costs, two-sided market interactions may yield multiple equilibria. Assume $\alpha_{1}<\bar{\alpha}=1$. Under our functional form assumptions, Eqs. (20) and (22) can be rewritten into

$$
\alpha_{0}=\frac{k_{m}}{2 e^{\left(-\lambda I_{0}\right)}\left(1+\lambda I_{0}-k_{c}\right) Z_{0}} \quad(\mathrm{~L} 1), \quad I_{0}=\frac{\left(\frac{1+\tau_{c}}{1+f_{c}}\right)^{1-\alpha_{0}^{2}} k_{c} / \lambda}{\left(\frac{1+\tau_{c}}{1+f_{c}}\right)^{1-\alpha_{0}^{2}}-\exp \left(s \alpha_{0}^{2}\right)}
$$

where $s$ is a scaler determined by the model parameters (See Appendix A2).

For plausible parameter values, we plot Eqs. (L1) and (L2) in Fig. 4, which illustrates the interactions between merchant and consumer card adoption. ${ }^{19}$ For a given pair of card fees $\left(f_{m}, f_{c}\right)$, there exist two equilibria with positive levels of card adoption (Note that no adoption is an equilibrium as well): a high-adoption equilibrium $\left(I_{0}^{*}, \alpha_{0}^{*}\right)$ and a low-adoption equilibrium $\left(I_{0}^{\prime}, \alpha_{0}^{\prime}\right)$. The high equilibrium is stable while the low equilibrium is not, so we always select the stable high-equilibrium in our following analysis. ${ }^{20}$

\footnotetext{
${ }^{19}$ Eq. (L1) implies $\left.\alpha_{0}\right|_{I_{0} \longrightarrow 0} \longrightarrow \frac{k_{m}}{2\left(1-k_{c}\right) Z_{0}}>0,\left.\alpha_{0}\right|_{I_{0} \rightarrow \infty} \longrightarrow \infty, \frac{d \alpha_{0}}{d I_{0}}>0, \quad \frac{d^{2} \alpha_{0}}{d I_{0}^{2}}>0$; and Eq. (L2) implies $\left.I_{0}\right|_{\alpha_{0} \rightarrow 0} \rightarrow \frac{\left(\frac{1+\tau_{c}}{1+f_{c}}\right) k_{c} / \lambda}{\left(\frac{1+\tau_{c}}{1+f_{c}}\right)-1}>0,\left.\alpha_{0}\right|_{I_{0} \longrightarrow \infty} \longrightarrow \alpha^{u}=\left(\frac{\ln \left(\frac{1+\tau_{c}}{1+f_{c}}\right)}{\ln \left(\frac{1+\tau_{c}}{1+f_{c}}\right)+s}\right)^{1 / 2}<1, \frac{d \alpha_{0}}{d I_{0}}>0, \quad$ and $\frac{d^{2} \alpha_{0}}{d I_{0}^{2}}<0$.

${ }^{20}$ The idea of using stability to select an equilibrium goes back to Cournot (1838), who provided a dynamic adjustment argument by imagining sequential play by each agent myopically best-responding to all rivals. This is referred to as best-reply dynamics, and when the process converges, the solution is termed stable (Fudenberg and Tirole, 1991). In our model context, the existence of multiple equilibria implies that when the payment card was initially introduced, the card network may need to push the card adoption to overcome the instable (low-adoption) equilibrium to achieve the stable (high-adoption) equilibrium. This could be interpreted as the adoption hurdles due to merchant and/or consumer learning.
} 


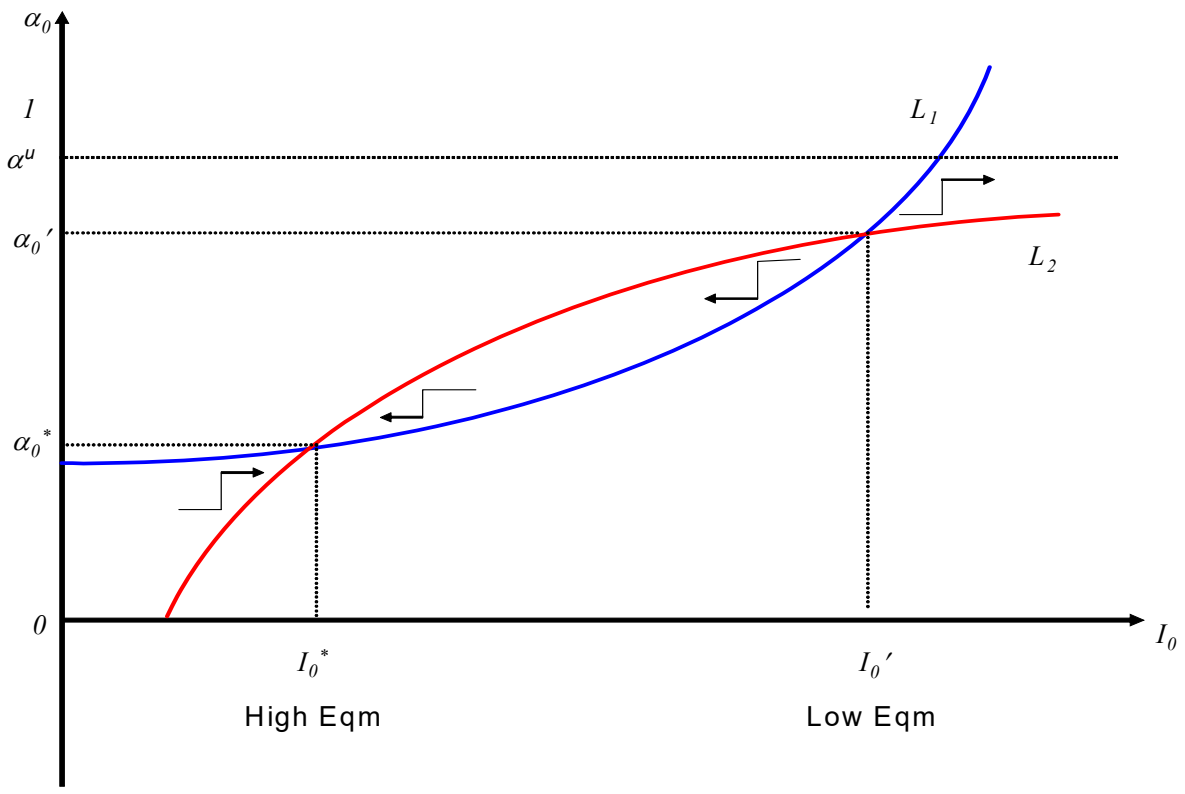

Figure 4: Interaction of Merchants and Consumers in Card Adoption

Second, under Assumption F3, the optimal card adoption thresholds $\left(\lambda I_{0}^{*}, \alpha_{0}^{*}\right)$ depend on $d$ but not $\lambda$. As a result, changing the mean consumer income $1 / \lambda$ just shifts the profit function $\pi(d ; \lambda)$ proportionally. We can also verify that for a given $\lambda$, the network's optimal profit $\pi(d ; \lambda)$ is approximately linear in $d$. Therefore, the profit function can be simplified as

$$
\pi(d ; \lambda)=\frac{1}{\lambda}\left(a_{0}-a_{1} d\right),
$$

where $a_{0}$ and $a_{1}$ are scalers determined by the model parameters (see Appendix A3 for the detailed proof).

\subsubsection{Dynamic Equilibrium}

The within-period equilibrium can then be embedded in the dynamic analysis. Note that Assumption F4 implies a R\&D investment function that

$$
R_{t}=\phi \frac{d_{t}}{\lambda_{t}}\left[\frac{d_{t}}{d_{t+1}}-1\right]^{\frac{1}{\gamma}} \text { with } 1>\gamma>0 .
$$

The function, in the spirit of adjustment costs studied in the macro/investment models (e.g., Hall, 2001, 2004), is strictly increasing and convex in technological progress $\left(d_{t} / d_{t+1}\right)$ 
and constant return to scale in $\left(d_{t}, d_{t+1}\right) \cdot{ }^{21}$

We can then formulate the dynamic problem of the card network as follows:

$$
V\left(d_{t} ; \lambda_{t}\right)=\max _{d_{t+1}} \pi\left(d_{t} ; \lambda_{t}\right)-\phi \frac{d_{t}}{\lambda_{t}}\left[\frac{d_{t}}{d_{t+1}}-1\right]^{\frac{1}{\gamma}}+\beta V\left(d_{t+1} ; \lambda_{t+1}\right) .
$$

Given the profit function $\pi\left(d_{t} ; \lambda_{t}\right)$ is represented by Eq. (32), the dynamic optimization problem (33) can be explicitly solved for a balanced-growth path (See Appendix A3 for the detailed proof).

\subsection{Calibration Results}

\subsubsection{Industry Background}

Given the functional forms of the model, we choose parameter values to match the U.S. payment card data from 1997-2008. ${ }^{22}$ During this period, credit and debit cards have become the most popular electronic payment means for retail transactions in the U.S. economy. The early history of general purpose credit cards in the U.S. can be traced back to 1950s when the Diners Club card was first launched, but not until 1970s had credit cards eventually picked up, with the market eventually becoming highly concentrated (Visa and MasterCard became the two largest credit card networks, followed by Amex and Discover). The introduction of debit cards was more recent. ATM and ATM cards were invented in 1970s. By adding the debit function, some of the ATM cards became debit cards in early 1980s, which could be used to pay at the point of sale. The adoption and usage of debit cards started to gain steam in the mid-1990s, and Visa, MasterCard and several ATM networks became dominant players (Hayashi et al., 2006).

Since the late 1990s, with the wide adoption of credit cards and rapid expansion of debit cards, the fees they charge have raised great controversies. The key issue is the asymmetric fees that card networks charge to merchants and consumers. In a card

\footnotetext{
${ }^{21}$ See Khan and Thomas (2008) for a comprehensive review of the adjustment cost literature. Our modeling of R\&D allows us to solve for a balanced growth path at the industry level. This is also related to the endogenous growth theories (e.g., see Aghion and Howitt 1998), though the focus there is to study how $R \& D$ could drive balanced growth at the aggregate economy level.

${ }^{22}$ Our sample starts from 1997 when the card fee data became available. The sample ends in 2008 because the adoption of credit and debit cards had almost saturated by then and we also want to avoid the disruption of the Great Recession.
} 
transaction, merchants are typically charged a much higher fee than consumers, with the major component being the interchange fee. Over time, despite rapid technological progress in the card industry, the fees charged to merchants continue to increase while the fees charged to consumers decline (and in some cases consumers pay a negative fee by receiving rewards). The controversy of payment card fees led to numerous lawsuits and Congress hearings, and eventually the Federal Reserve was mandated by Congress to regulate debit card interchange fees in 2011.

While our model is about electronic payments in general, credit and debit cards are particularly good applications. Note that while our model does not consider credit functionality, it is still very relevant for credit cards. In the late 1990 s, about $78 \%$ of U.S. consumers adopted credit cards, but among them about 50\% cardholders only used the payment function of the cards (i.e., by paying off all purchases made with the card at the end of each month, not utilizing any revolving credit), so-called "convenience users." However, a consumer's spending on a credit card is limited by the card's credit line, so credit cards may not cover the consumer's all payment needs. This gave room for the fast adoption of debit cards since the mid-1990s, especially among lower-income consumers who are constrained by their credit limits (Zinman, 2009). Because debit cards do not provide the credit function, they serve purely as a payment device. In 2008, credit card were used in 26.5 billion transactions worth about $\$ 2.1$ trillion in the U.S. economy, while debit cards were used in 34 billion transactions worth about $\$ 1.3$ trillion.

\subsubsection{Model Fit}

To calibrate the model, we collected data on the pricing, adoption and usage for credit and debit cards. The pricing data we collected include the interchange fees charged by Visa, MasterCard and major debit card networks between 1997-2008 and we convert them into merchant card fees by adding a reasonable merchant acquiring fee. ${ }^{23}$ We also collected

\footnotetext{
${ }^{23}$ Data sources: Interchange fee data are from the American Banker (various issues). We then calculate the average credit card interchange fee based on credit card data for Visa and MasterCard. We also calculate the value weighted average debit card interchange fee based on debit card data for Visa, MasterCard, and top PIN debit networks. We then add a merchant acquiring fee on top of the interchange fee so that the total merchant discount rate for accepting credit cards is around $3 \%$ in the late 2000s, which is about the industry standard (e.g., Square Inc. charges merchants $2.75 \%$ for each swiped credit card transaction and $3.5 \%$ per manually-entered credit card transaction).
} 
the data on consumers' adoption of credit and debit cards in the same period, as well as annual transaction values for cash, credit card and debit card. ${ }^{24}$ We then calibrate our model to match these patterns. Our calibrated model also delivers additional patterns, including the decline in consumer card fees and card operation costs, which are consistent with industry observations.

Table 1. Parameter Values for Model Calibration

\begin{tabular}{lccllc}
\hline \hline \multicolumn{1}{c}{ Parameter Definition } & & Value & \multicolumn{1}{c}{ Parameter Definition } & & Value \\
\hline Merchant cost of handing cash & $\tau_{m}$ & $4.0 \%$ & Initial value of card service costs & $d_{0}$ & $2.25 \%$ \\
Consumer cost of handing cash & $\tau_{c}$ & $2.5 \%$ & R\&D function curvature & $\gamma$ & 0.5 \\
Merchant cost of adopting card & $k_{m}$ & $2.5 \%$ & R\&D efficiency scaler & $\phi$ & 10 \\
Consumer cost of adopting card & $k_{c}$ & $0.3 \%$ & Initial value of mean income & $1 / \lambda_{0}$ & 21,215 \\
Merchant cost of goods & $\mu_{\alpha}$ & 1 & Growth rate of mean income & $g_{I}$ & $2 \%$ \\
\hline
\end{tabular}

Parameter values used for the calibration are reported in Table 1. We set merchant cost of handling cash $\tau_{m}=4 \%$, which gives the upper limit of merchant card fee implied by the model. We set consumer cost of handling cash $\tau_{c}=2.5 \%$. We calibrate merchants' card adoption cost $k_{m}=2.5 \%$ of the consumer mean income, which implies an adoption cost about $\$ 500$ in 1997 . Consumer card adoption cost is set as $k_{c}=0.3 \%$, which implies an adoption cost about $\$ 60$ in 1997 . These numbers allow the model to match the card adoption and usage pattern in the data. ${ }^{25}$ We set the mean consumer income to be $\$ 21,215$ in 1997 with an average growth rate 2\%. This is derived from the U.S. Census data on deflated annual Personal Consumption Expenditures. ${ }^{26}$ Because merchant cost of goods $\mu_{\alpha}$ plays no role in our analysis except for scaling utility, we normalize that $\mu_{\alpha}=1$. We

\footnotetext{
${ }^{24}$ Data sources: The data on consumers' adoption of credit and debit cards are from the Survey of Consumer Finance (various years). The data on annual transaction values for cash, credit card and debit card are from the Nilson Report (various issues).

${ }^{25}$ Note that if we set symmetric costs for merchants and consumers $\tau_{c}=\tau_{m}$ and $k_{m}=k_{c}$, the model would deliver the same qualitative pattern of card pricing that the merchant card fee continues to increase over time while consumer card fee continues to decrease.

${ }^{26}$ In our model, a consumer's income equals her total purchases. Therefore, we use U.S. Census data on deflated annual Personal Consumption Expenditure (PCE) from 1997-2008 to calibrate the consumer income/purchase in our model. Using the estimates from the Nilson Report, we count purchases of goods and services as $78 \%$ of the PCE (the rest are nonpurchases - transactions for which no payment was made, such as food and lodging received by employees).
} 

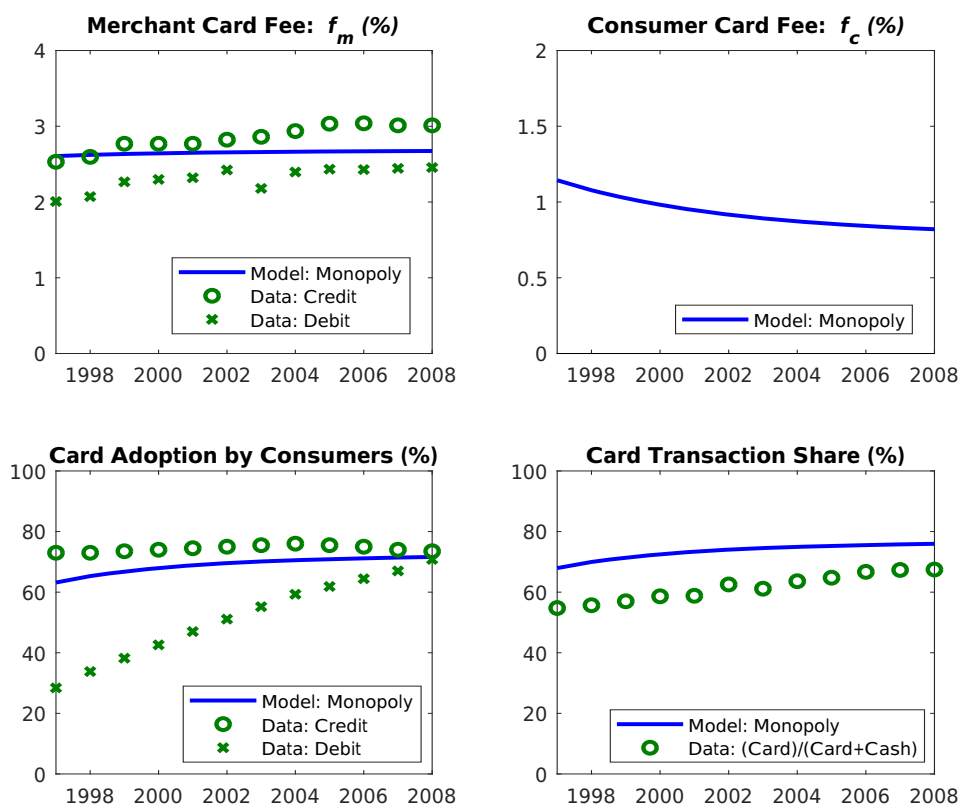

Figure 5: Model Calibration

set initial value of card service cost $d_{0}=2.25 \%$, below the costs of handing cash. We set R\&D function parameters $\gamma=0.5$ and $\phi=10$ to match the dynamic pattern of data.

The model calibration yields patterns that are consistent with data, as shown in Fig. 5. The model generates a rising merchant fee over time and the level falls into the range between the average merchant fees charged by credit and debit cards in the data. The model generates a declining consumer fee over time, which is consistent with an increase of consumer card rewards during the period. ${ }^{27}$ The model also generates increasing adoption of cards by consumers similar to the data, and the share of card transaction rises in parallel with the data (for the sum of credit and debit cards) though at a slightly higher level.

\footnotetext{
${ }^{27}$ It is hard to estimate the average consumer card fees. Credit card users, if not rolling over any balances on their cards, may not need to pay a fee (or even receive rewards) for each card transaction. However, there are chances that some of those users may end up borrowing from their cards, in which case they then need to pay a very high interest rate for every transaction made. For debit cards, consumers often need to pay a PIN fee for using online debit cards in our sample period, but some of them may also receive rewards. On the other hand, industry studies show that card rewards have gained increasing popularity over time. In 2001, less than a quarter of credit card offers included the promise of a rewards program. But by 2005, the share was 58 percent, according to Mail Monitor, a unit of consumer research company Synovate. A similar trend also happened to debit cards, as shown in 2005/2006 Study of Consumer Payment Preferences conducted by the American Bankers Association and Dove Consulting.
} 

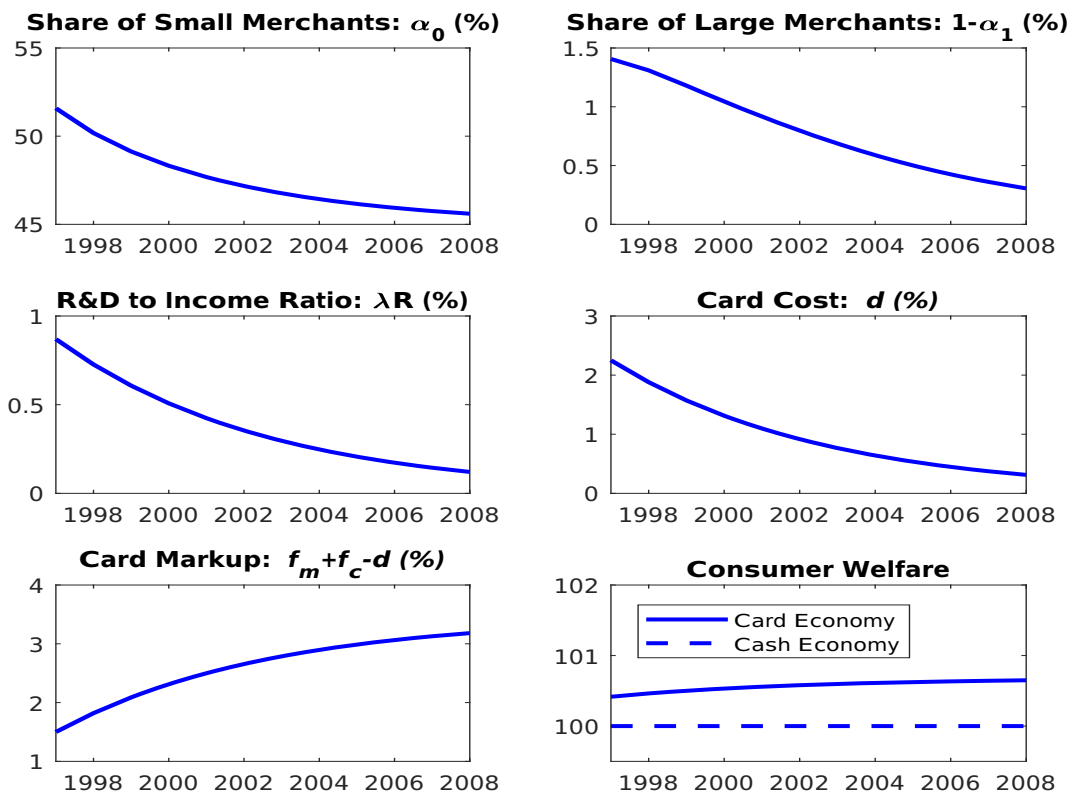

Figure 6: Model Calibration (continued)

Beyond comparing with the data, Fig. 6 reports additional patterns generated by the model that of interest. First, the overall card adoption by merchants increases over time, with the shares of large merchants (i.e., those who accept both cash and card but charge prices lower than cash-only stores) and small merchants (who accept cash only) declining. Second, the card network invests in R\&D to reduce card service costs $d$, with the $R \& D$ expenditure to mean income ratio declining over time. Third, with the decline in card costs, the card network charges an increasing markup, which together with a rising card spending share indicates that the card network earns an increasing profit. Finally, consumer welfare in each period, scaled by the mean income, continues to rise, while in a cash economy it would be constant (which we normalize to be 100 in the figure). The detailed derivation of consumer welfare is explained next.

\section{$5 \quad$ Welfare and Policy Analysis}

This section provides a normative analysis of the card payment system. First, we show introducing payment cards increases welfare for both card adopters and nonadopters. 
Second, we show a Ramsey social planner who maximizes consumer and social welfare using the same set of pricing and R\&D instruments would behave differently than a profitmaximizing platform. Finally, we discuss welfare implications of policy interventions.

\subsection{Payment Card and Welfare Improvement}

In our model framework, introducing the payment card improves every consumer's welfare, even for those who do not adopt card. This can be shown in the following welfare comparison between a cash economy and a card economy.

Recall in a cash economy, an individual consumer $I$ enjoys the utility level $U_{I, h}$ such that

$$
\ln U_{I, h}=\int_{0}^{\bar{\alpha}} \frac{\alpha}{E(\alpha)} \ln \frac{\alpha I}{E(\alpha)\left(1+\tau_{c}\right) p_{\alpha, h}} d G(\alpha)
$$

Consider the same economy but with the introduction of the payment card. A consumer decides whether to adopt the card based on her income. For a consumer who adopts card (i.e. $I \geq I_{0}$ ), her utility $U_{I, d}^{d}$ implies that

$$
\ln U_{I, d}^{d}=\int_{0}^{\alpha_{0}} \frac{\alpha}{E(\alpha)} \ln \frac{\alpha\left(I-K_{c}\right)}{E(\alpha)\left(1+\tau_{c}\right) p_{\alpha, h}} d G(\alpha)+\int_{\alpha_{0}}^{\bar{\alpha}} \frac{\alpha}{E(\alpha)} \ln \frac{\alpha\left(I-K_{c}\right)}{E(\alpha)\left(1+f_{c}\right) p_{\alpha, d}} d G(\alpha)
$$

while a nonadopter (i.e. $I<I_{0}$ ) derives the utility level $U_{I, d}^{h}$ such that

$\ln U_{I, d}^{h}=\int_{0}^{\min \left(\alpha_{1}, \bar{\alpha}\right)} \frac{\alpha}{E(\alpha)} \ln \frac{\alpha I}{\left(1+\tau_{c}\right) p_{\alpha, h} E(\alpha)} d G(\alpha)+\int_{\min \left(\alpha_{1}, \bar{\alpha}\right)}^{\bar{\alpha}} \frac{\alpha}{E(\alpha)} \ln \frac{\alpha I}{\left(1+\tau_{c}\right) p_{\alpha, d} E(\alpha)} d G(\alpha)$.

Therefore, a consumer receives different welfare gain depending on her income. For a card adopter, her welfare gain is

$$
\begin{aligned}
\ln U_{I, d}^{d}-\ln U_{I, h}= & \int_{\alpha_{0}}^{\min \left(\alpha_{1}, \bar{\alpha}\right)} \frac{\alpha}{E(\alpha)} \ln \left(\frac{p_{\alpha, h}}{p_{\alpha, d}}\right) d G(\alpha)+\int_{\min \left(\alpha_{1}, \bar{\alpha}\right)}^{\bar{\alpha}} \frac{\alpha}{E(\alpha)} \ln \left(\frac{p_{\alpha, h}}{p_{\alpha, d}}\right) d G(\alpha) \\
& +\frac{E_{\alpha \geqslant \alpha_{0}}(\alpha)}{E(\alpha)} \ln \left(\frac{1+\tau_{c}}{1+f_{c}}\right)+\ln \left(\frac{I-K_{c}}{I}\right)
\end{aligned}
$$

while for a nonadopter, her welfare gain is

$$
\ln U_{I, d}^{h}-\ln U_{I, h}=\int_{\min \left(\alpha_{1}, \bar{\alpha}\right)}^{\bar{\alpha}} \frac{\alpha}{E(\alpha)} \ln \left(\frac{p_{\alpha, h}}{p_{\alpha, d}}\right) d G(\alpha) .
$$


Equations (34) and (35) are intuitive: A card consumer enjoys utility gains from shopping at card-accepting stores in both categories (1) and (2), subject to the card adoption and usage costs, while a cash consumer only benefits from lower retail prices charged by merchants in category (1). In fact, we can derive the following proposition.

Proposition 2 No consumer is worse off given any positive measure of card adoption.

Proof. Equation (35) shows that cash consumers' welfare cannot be lower in a card economy than in a cash economy, given that $p_{\alpha, d} \leq p_{\alpha, h}$ in merchant category (1). Equation (34) shows this also holds true for the marginal card consumers $I=I_{0}$, while all other card consumers $I>I_{0}$ are strictly better off in the card economy.

The findings of Proposition 2 stand in contrast to the previous studies (e.g., Rochet and Tirole 2002, 2011), which argue that cash consumers subsidize card consumers. In our setting, because cards is a more efficient payment means, cash consumers are indeed subsidized by card consumers. However, this does not mean that cash consumers' welfare cannot be further improved in a card economy, as we will study next.

\subsection{Ramsey Social Planner}

Given the utility measures described above, the Ramsey social planner would choose a sequence of card fees $\left(f_{c, t}, f_{m, t}\right)$ and $\mathrm{R} \& \mathrm{D}$ investment $R_{t}$ to maximize the present value of consumer welfare subject to the adoption incentive constraints of merchants and consumers as well as the network balanced-budget constraint each period. Because the Ramsey social planner makes zero profit for running the card network, it also maximizes the social welfare under those constraints. The Ramsey social planner's problem is analyzed as follows.

Within-Period Decision Within each period, for given values of card costs $d$ and R\&D investment $R$, the Ramsey social planner who runs the card network would choose $\left(f_{c}, f_{m}\right)$ to maximize consumer welfare with the revenue covering operation and R\&D expenditures. This means that

$$
U\left(d, R ; E(I), K_{m}, K\right)=\underset{f_{c}, f_{m}}{\operatorname{Max}} \int_{I_{0}}^{\infty} U_{I, d}^{d} d G(I)+\int_{0}^{I_{0}} U_{I, d}^{h} d G(I)
$$




$$
\begin{gathered}
\text { s.t. Eqs }(11),(17),(19),(20),(21),(22),(34),(35), \text { and } \\
\pi\left(d ; E(I), K_{m}, K_{c}\right)=\frac{E_{\alpha \geq \alpha_{0}}(\alpha) E_{I \geq I_{0}}\left(I-K_{c}\right)}{E(\alpha)\left(1+f_{c}\right)}\left(f_{c}+f_{m}-d\right) \geq R .
\end{gathered}
$$

To minimize distortion, the Ramsey social planner would always keep the constraint (37) binding.

Dynamic Decision To describe the dynamic problem, we add back the time subscript to each variable. The value function of the Ramsey social planner is as follows.

$$
\begin{gathered}
V\left(d_{t} ; E\left(I_{t}\right), K_{m, t}, K_{c, t}\right)=\max _{R_{t}} U\left(d_{t}, R_{t} ; E\left(I_{t}\right), K_{m, t}, K_{c, t}\right) \\
+\beta V\left(d_{t+1} ; E\left(I_{t+1}\right), K_{m, t+1}, K_{c, t+1}\right) \\
\text { s.t. } d_{t+1}=\Gamma\left(d_{t}, R_{t}\right),
\end{gathered}
$$

where $\Gamma$ is the $R \& D$ function.

Based on the same set of functional form assumptions and parameter values as above, we can solve the Ramsey social planner's problem and compare the result with that of the profit-maximizing network (See Appendix A4 for the detailed proof).

For illustrative purposes, we consider a hypothetical scenario that the Ramsey social planner takes over and runs the card network at the beginning of our sample period. Figures 7-8 compare the Ramsey outcome with the monopoly network case and show several important findings. First, both merchants and consumers enjoy lower fees under the Ramsey social planner, and unlike the monopoly case, both the merchant fee and the consumer fee decrease over time. These lead to higher card adoption and usage, which suggests that the market power of card networks does contribute to a slow diffusion of electronic payments. Second, under the Ramsey social planner, the share of large merchants whose sizes are large enough to attract both card and cash consumers is much higher and increasing over time. This suggests that cash users would benefit much more from electronic payments than under the monopoly network case. Third, the Ramsey social planner would conduct more $\mathrm{R} \& \mathrm{D}$, which results in a faster decline in cost service 

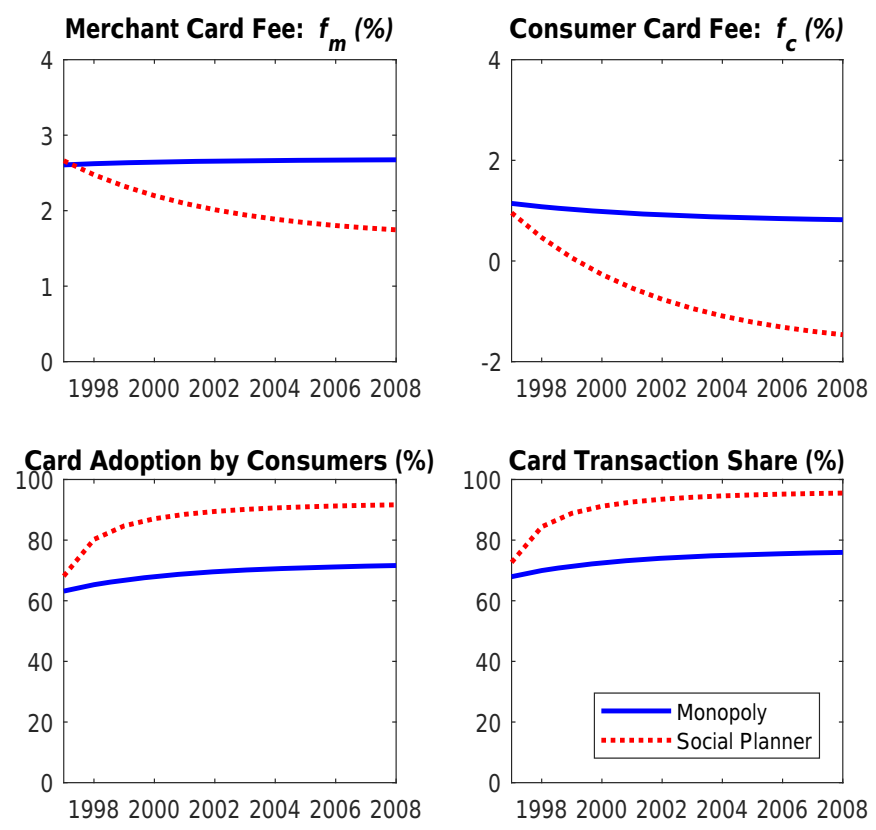

Figure 7: Monopoly Network vs. Ramsey Social Planner

cost. Finally, all things together, consumer welfare in each period increases faster under the Ramsey social planner, which is due to the fact that the Ramsey social planner charges a decreasing markup over time, while the monopoly charges an increasing one.

A few reasons explain why the monopoly network and the Ramsey social planner would behave differently. For the monopoly network, imposing a high merchant fee leads to high retail prices of goods and allows the network to extract more rents produced by replacing costly cash payments. Moreover, because the network does not earn profits from cash users, charging a high merchant fee reduces cross subsidies from card users to cash users through large merchants who serve both card and cash users. In contrast, the Ramsey social planner cares about consumers' real purchases rather than their nominal card spending, and cares about the welfare of both card and cash users. In terms of R\&D decisions, the monopoly only sees the benefit of increased profit, which is a subset of the social welfare that the social planner would value, so the monopoly makes less R\&D investment than the Ramsey social planner.

Note that in the Ramsey social planner case, because the network earns zero profit, consumer welfare equals social welfare. However, in the monopoly network case, evaluat- 

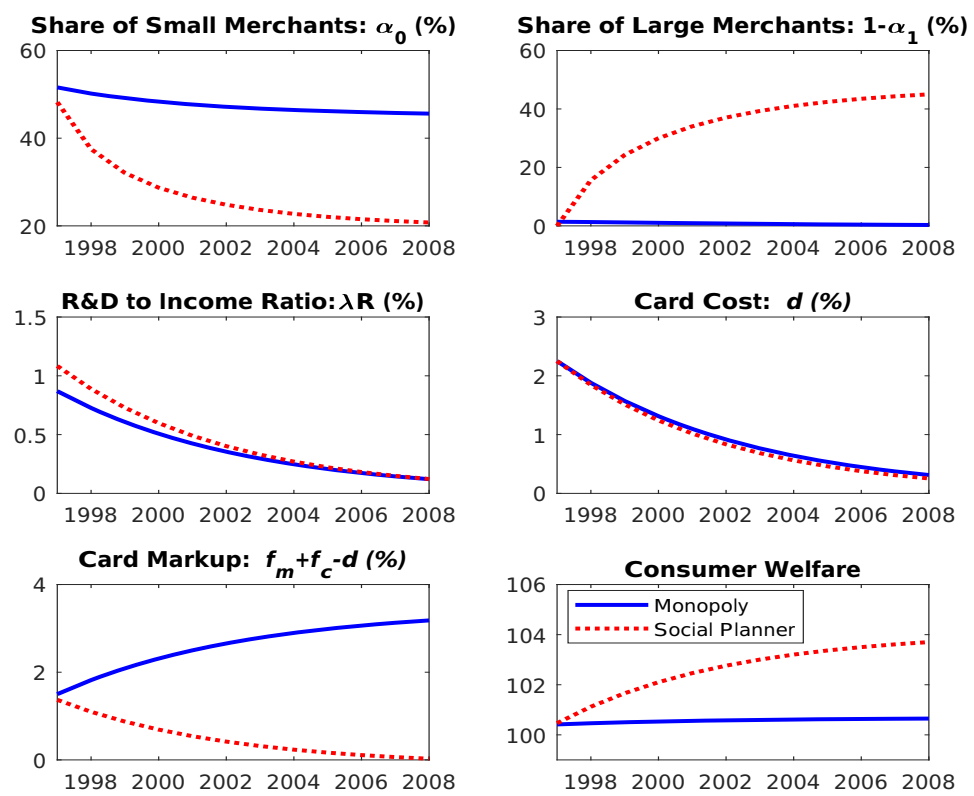

Figure 8: Monoply Network vs. Ramsey Social Planner (continued)

ing social welfare needs to take into account both consumer welfare and network profits by assigning appropriate weights to each. Here, we consider a natural approach by assuming that the monopoly network rebates its profits to consumers proportionally to consumers' income (e.g., consumers own shares of the network in proportion to their income). In so doing, we can assign consumption values to the network profits to calculate the total social welfare. Of course, there are other ways of assigning welfare weights to profits, and we keep the distinction between "consumer welfare" (without profit rebates) and "social welfare" (with profit rebates) in our following analysis.

Based on our calibrated model, consumers' income with profit rebates continues to follows an exponential distribution but just has a higher mean. Because the card adoption costs are proportional to the mean income, card adoption thresholds would remain unchanged for merchants and consumers. Figure 9 compares social welfare under the monopoly network versus the Ramsey social planner. The results show that at the beginning years, because the social planner invests more in $R \& D$, social welfare in a given period is actually lower than that under the monopoly, even though consumer welfare (without profit rebates) is higher. However, social welfare in each period grows faster 


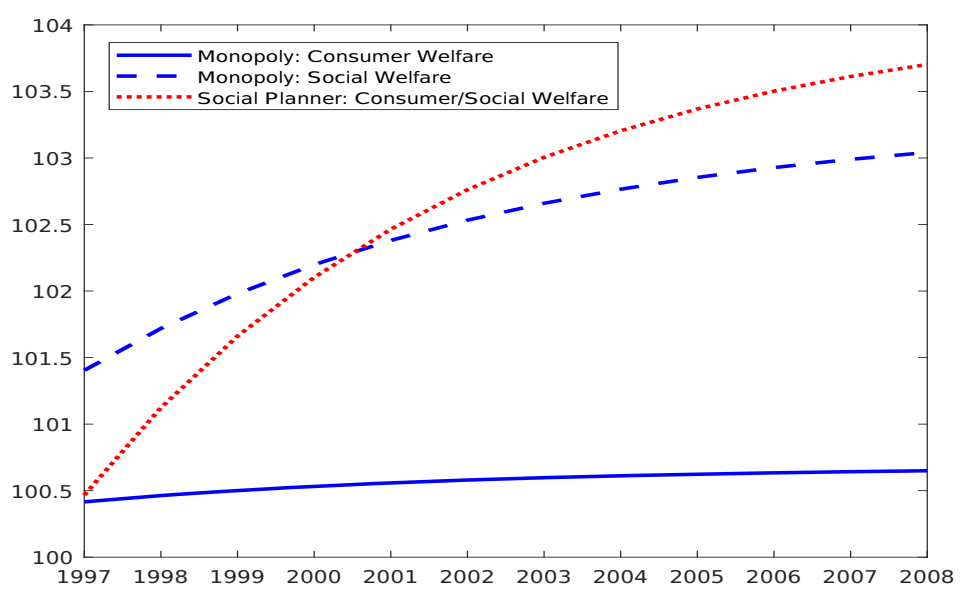

Figure 9: Comparing Social Welfare

under the Ramsey social planner and surpasses that under the monopoly in a few years and the gap becomes wider over time.

\subsection{Policy Experiments}

In this section, we use our calibrated model to study two regulatory approaches on payment cards. One is the marginal-cost pricing regulation, and the other is the merchant fee cap regulation. These two approaches are the most popular ones in policy debates, and can each be justified by some existing theories.

The marginal-cost pricing regulation can find its root in traditional one-sided markets, and a naive argument is to require the card network to set fees to merchants and consumers equal to the marginal cost of serving each side, which implies $f_{m}=d_{m}$ and $f_{c}=d_{c}$. However, as Baxter (1983) pointed out, because payment card markets are two-sided, it would be decidedly inefficient to block side payments between merchants and consumers. Instead, the socially optimal card pricing should be $f_{m}+f_{c}=d_{m}+d_{c}$. While this approach considers the two-sided nature of card markets, it is based on a static analysis and ignores the endogenous R\&D of card networks.

On the other hand, the merchant fee cap regulation has been adopted in many countries. Compared with the marginal-cost pricing regulation, it is easier to implement because it regulates only the fee on the merchant side. In practice, the merchant (inter- 

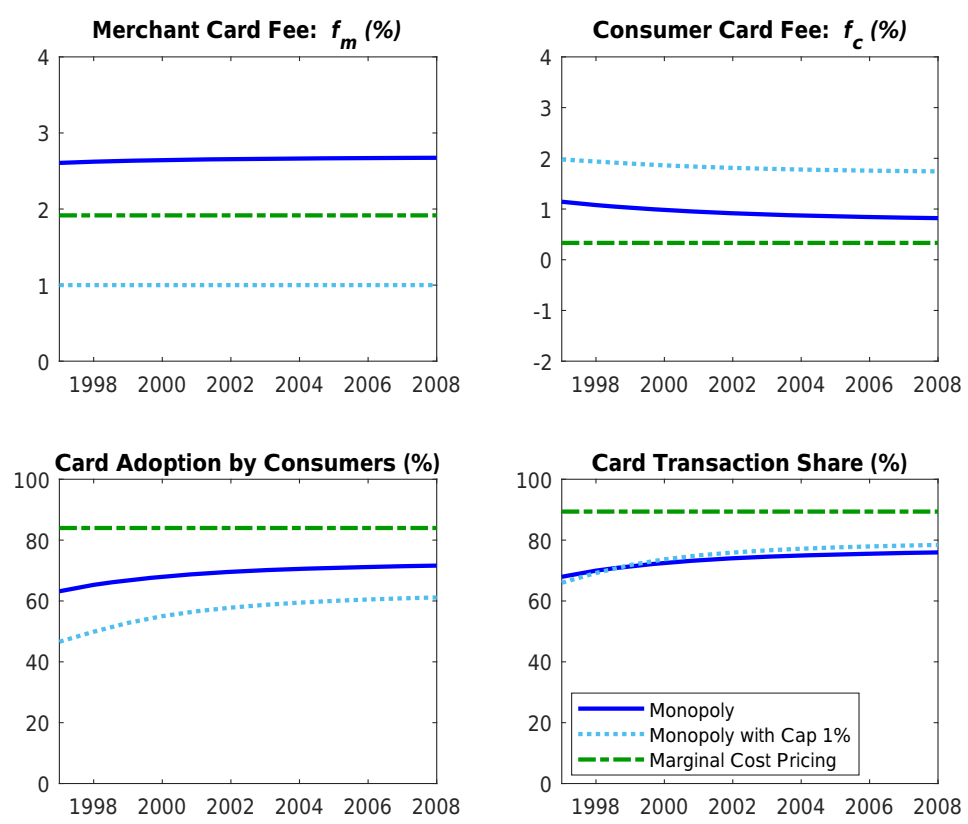

Figure 10: Policy Experiments

change) fee cap is rationalized either by an issuer-cost argument (e.g., in Australia and the U.S.) or by a merchant-benefit argument (e.g., in the EU).

We simulate our calibrated model for each policy experiment by assuming the regulation is implemented at the beginning year of our sample period. For the marginal-cost pricing regulation, we require the card network to set card fees $\left(f_{m, t}, f_{c, t}\right)$ to maximize consumer welfare subject to the zero markup constraint $f_{m, t}+f_{c, t}=d_{t}$. Figures 10 and 11 show the results. Comparing with the unregulated monopoly case, the regulated network lowers card fees to both merchants and consumers. This boosts card adoption by both sides and the fraction of large merchants who serve both card and cash users increases substantially. All these result in a higher level of consumer welfare. However, this regulation deprives the card network of R\&D incentive and resources, so the card service $\operatorname{cost} d_{t}$ stays at the initial level $d_{0}$. Figure 12 shows that comparing with the unregulated monopoly and the Ramsey social planner, this regulation yields a lower level of social welfare in each period except for the initial few years.

We also simulate alternative regulations that cap the merchant fee at various levels. Figures 10 and 11 show the results for the cap set at 1\%. Given the binding cap on the 

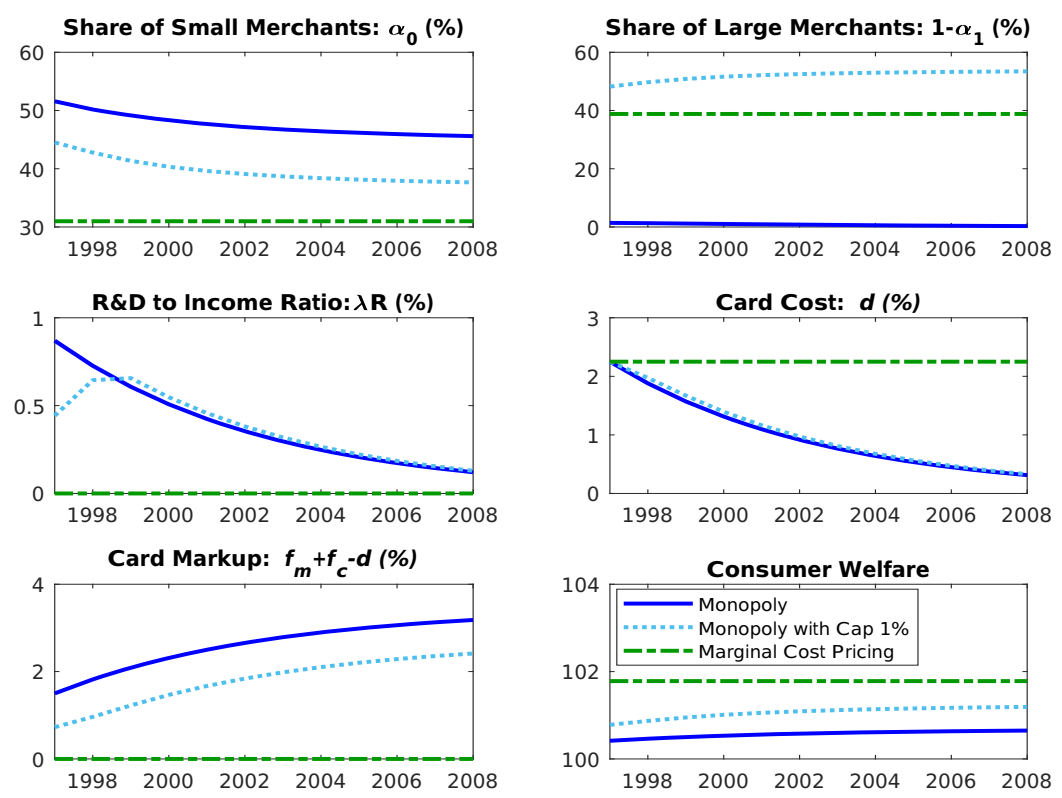

Figure 11: Policy Experiments (continued)

merchant fee, the card network turns to a higher consumer fee to make up the lost revenue. As a result, consumer card adoption is lower but the adoption by merchants (including large merchants who serve both card and cash users) becomes higher comparing with the unregulated monopoly case. The card transaction share does not change much but the markup is lower, so the network profit is reduced. As a result, the card network's R\&D spending is constrained in the first few years, which leads to a slower decline in card service costs until the late stage of the sample period. ${ }^{28}$ Consumer welfare in each period is higher under the merchant fee cap regulation compared with the unregulated monopoly case, but as shown in Fig. 12, social welfare gets lower in the early years before it turns higher in the longer run.

Figure 13 provides welfare comparison between different scenarios by computing the present values of consumer and social welfare at the beginning year of our sample period,

\footnotetext{
${ }^{28}$ Our calibrated model shows that the merchant fee cap regulation reduces the card network's profit level but not the marginal return of doing R\&D. Recall the monopoly network's profit function (32) $\pi(d ; \lambda)=\frac{1}{\lambda}\left(a_{0}-a_{1} d\right)$. The merchant fee cap reduces the value of $a_{0}$ but not the value of $a_{1}$ (and even increases it slightly), and $a_{1}$ determines the rate of cost decline at the balanced growth path. Therefore, the decline in card service cost $d_{t}$ does not slow down except for the first few years when the network's optimal R\&D spending is constrained by its period profit.
} 


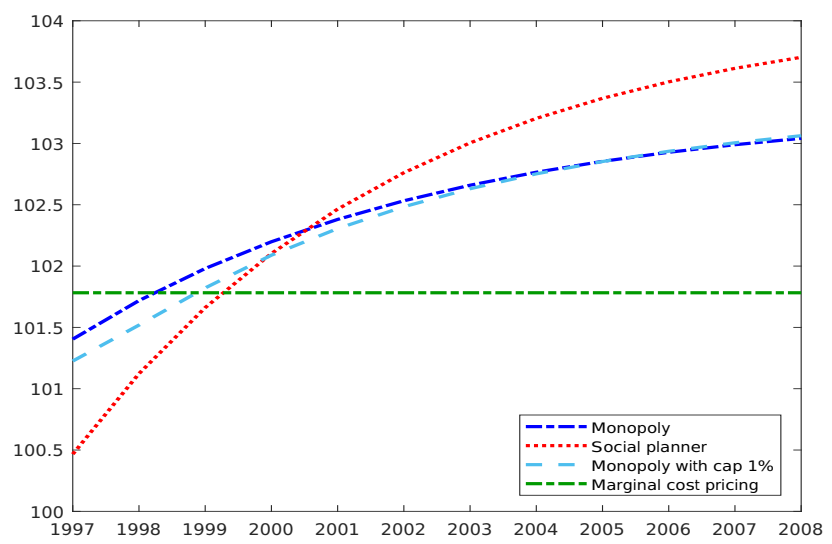

Figure 12: Comparing Social Welfare of Policy Experiments

with the present value of the cash economy being normalized to 100 . The marginal-cost pricing regulation maximizes consumer welfare in a static setting, but it leaves no profit for the card network to conduct R\&D. As a result, it yields a higher present value of consumer welfare than the unregulated monopoly, but the present value of social welfare is lower. In comparison, the merchant fee cap regulation redistributes between network profit and consumer welfare but without hurting much the network's R\&D. We do see the lower the cap, the higher the consumer welfare, but the social welfare (which slightly increases in the cap value) changes little compared with the unregulated monopoly.

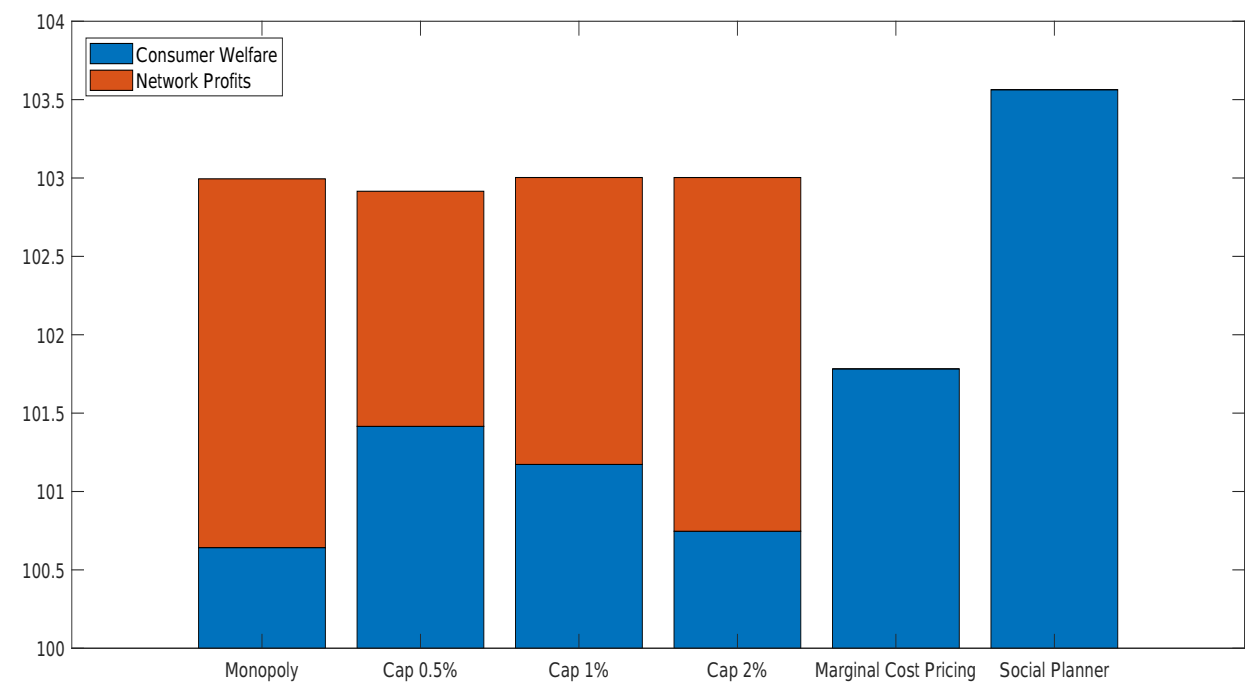

Figure 13. Comparing Present Values of Consumer and Social Welfare 


\section{Conclusion}

In this paper, we provide a new analysis of payments system evolution and the accompanying competitive efficiency issues. Our theory lays out a two-sided market environment where consumers and merchants make adoption and usage decisions for electronic payments. The economics of these payment choices, specifically the fixed cost of adoption and marginal benefits of usage intertwined with the heterogeneity of consumer income and merchant size, together with price coherence, generate nontrivial network externalities. This setting is embedded in a fully dynamic model, in which a monopoly electronic payment network sets usage fees and conducts R\&D to lower costs. We calibrate the model to the U.S. payment card pricing, adoption and usage data, and conduct welfare and policy analysis.

Our analysis suggest that the market power of electronic payment networks plays important roles in explaining the slow adoption of electronic payments. In contrast, a Ramsey social planner who aims to maximize consumer and social welfare would set lower usage fees and conduct more R\&D, thus achieving higher levels of adoption and usage of electronic payments. We also consider several regulatory interventions. Our findings suggest that while marginal-cost pricing regulation could maximize consumer welfare in a static setting, it shuts off the card network's R\&D and may reduce social welfare in a dynamic setting. In comparison, the merchant fee cap regulation may improve consumer welfare without causing much dynamic inefficiency.

Our analysis can be extended in several directions. First, our model assumes that the fixed costs of adopting electronic payments move together with the consumer mean income. This is a simplifying assumption that allows our analysis to focus on cost-reducing technological progress. In case data becomes available, it would be useful to study how the adoption costs actually change over time and how that affects diffusion of electronic payments. Second, by assuming consumer income follows an exponential distribution, our analysis focus on the change in the average income while holding the income inequality fixed. For future research, it might also be interesting to study the effect of income inequality, perhaps by choosing more flexible distributions. Third, the competitive merchants that we consider provides a first approximation to modeling retail market competition. It 
would be interesting to study alternative merchant market structures and the effects on payment system evolution. Finally, one may extend the framework to consider multiple payments networks. It would be interesting to study how cooperation and competition among networks affect the market outcome.

\section{References}

[1] Aghion, Philippe and Peter Howitt (1998), Endogenous Growth Theory. MIT Press, Cambridge, MA.

[2] Baxter, William (1983), "Bank Interchange of Transactional Paper: Legal Perspectives," Journal of Law and Economics 26: 541-588.

[3] Dragulescu, A. and V.M. Yakovenko, (2001) "Evidence for the Exponential Distribution of Income in the USA," European Physical Journal B 20: 585-589.

[4] Evans, David and Richard Schmalensee (2005), Paying with Plastic: The Digital Revolution in Buying and Borrowing 2d Ed. MIT Press, Cambridge, MA.

[5] Fudenberg, Drew and Jean Tirole (1991), Game Theory. MIT Press, Cambridge, MA.

[6] Hall, Robert E. (2001), "The Stock Market and Capital Accumulation," American Economic Review 91(5): 1185-1202.

[7] Hall, Robert E. (2004), "Measuring Factor Adjustment Costs," Quarterly Journal of Economics 119(3): 899-927.

[8] Hayashi, Fumiko, Richard Sullivan, and Stuart E. Weiner (2006). A Guide to the ATM and Debit Card Industry: 2006 Update. Federal Reserve Bank of Kansas City.

[9] Kahn, Charles and William Roberds (2009), "Why Pay? An Introduction to Payments Economics," Journal of Financial Intermediation 18: 1-23.

[10] Khan, Aubhik and Julia Thomas (2008), "Adjustment Costs," The New Palgrave Dictionary of Economics. Palgrave Macmillan, London.

[11] Kiyotaki, Nobuhiro and Randall Wright (1989), "On Money as a Medium of Exchange," Journal of Political Economy 97, 927-954. 
[12] Lagos, Ricardo and Randall Wright (2005), "A Unified Framework for Monetary Theory and Policy Analysis," Journal of Political Economy, 113, 463-484.

[13] McAndrews, James and Zhu Wang (2012), "The Economics of Two-Sided Payment Card Markets: Pricing, Adoption and Usage," Federal Reserve Bank of Richmond Working Paper No. 12-06.

[14] Mester, Loretta (2012), "Changes in the Use of Electronic Means of Payment, 19952010, An Update Using the Recently Released 2010 Survey of Consumer Finances," Federal Reserve Bank of Philadelphia Business Review, Third Quarter, 25-36.

[15] Nosal, Ed and Guillaume Rocheteau (2011), Money, Payments, and Liquidity, MIT Press.

[16] Rochet, Jean-Charles and Jean Tirole (2002), "Cooperation among Competitors: Some Economics of Payment Card Associations," RAND Journal of Economics, 33(4), 549-570.

[17] Rochet, Jean-Charles and Jean Tirole (2011), "Must-Take Cards: Merchant Discounts and Avoided Costs," Journal of the European Economic Association, 9 (3): 462-495.

[18] Rysman, Marc and Julian Wright (2014), "The Economics of Payment Cards," Review of Network Economics, 13: 303-353.

[19] Shy, Oz and Zhu Wang (2011), "Why Do Payment Card Networks Charge Proportional Fees?" American Economic Review, 101 (4): 1575-1590.

[20] Wright, Julian (2003), "Optimal Card Payment Systems," European Economic Review, 47: 587-612.

[21] Zinman, Jonathan (2009), "Debit or Credit?" Journal of Banking and Finance, 33(2): 358-366. 


\section{Appendix:}

\section{A1. Card Adoption by Consumer Income and Merchant Size ${ }^{29}$}

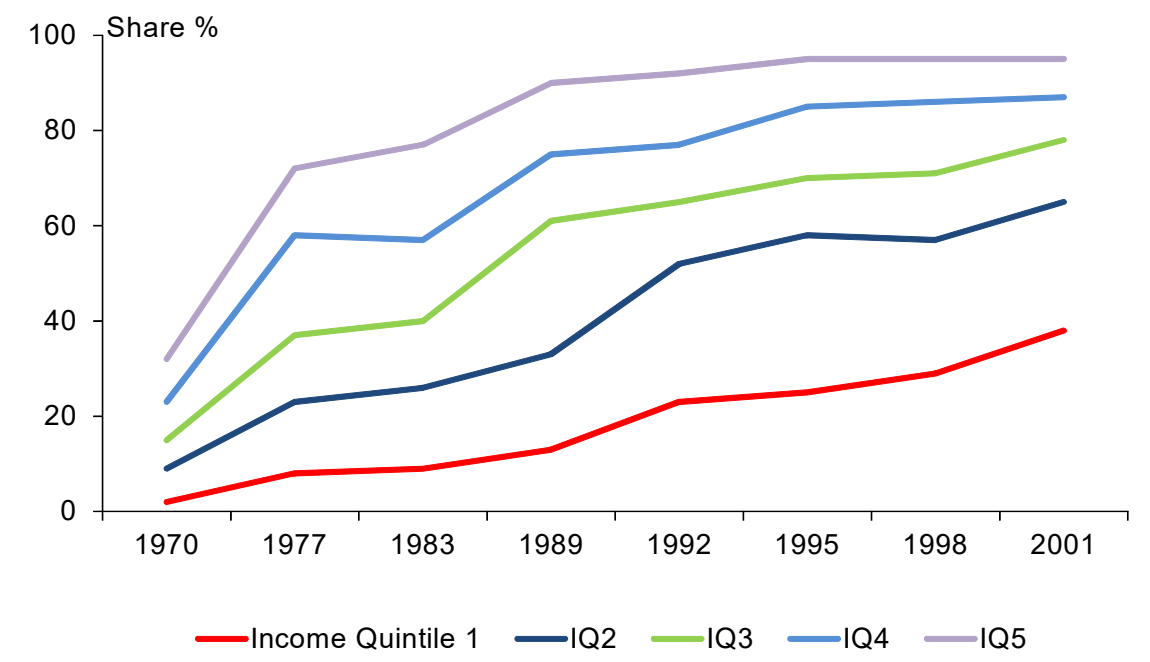

Figure A1(a): Percentage of U.S. Households Holding Credit Cards

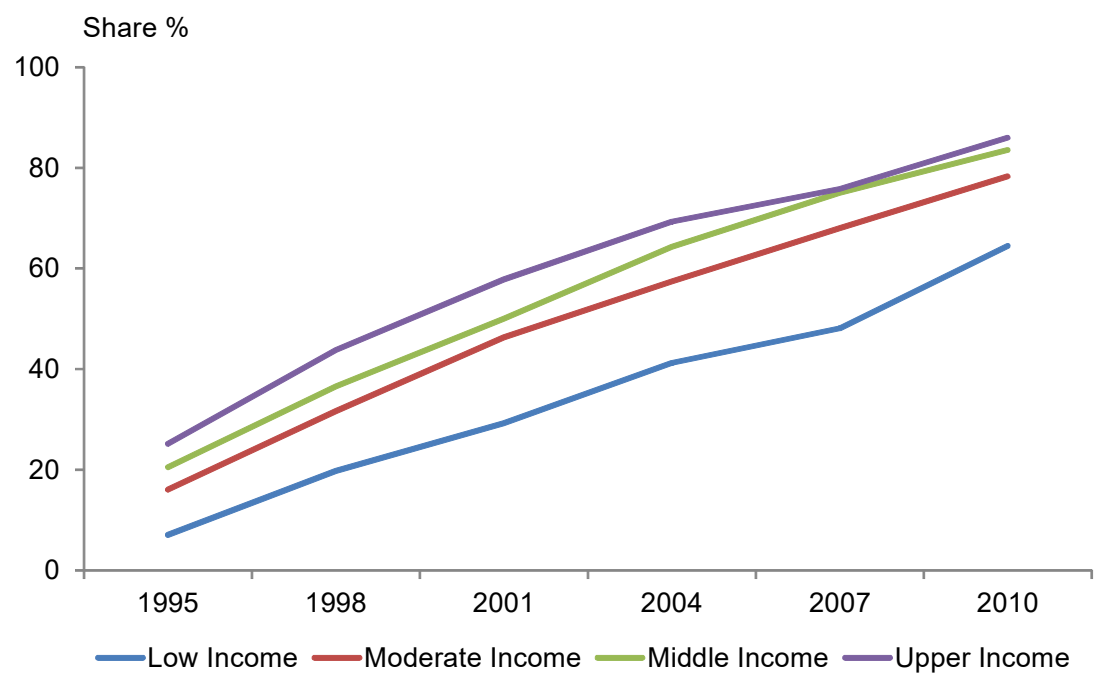

Figure A1(b): Percentage of U.S. Households Using Debit Cards

\footnotetext{
${ }^{29}$ Data sources: Mester (2012) and Evans and Schmalensee (2005). They also show similar adoption and usage patterns for other electronic payment means, such as smart cards and automatic bill paying.
} 


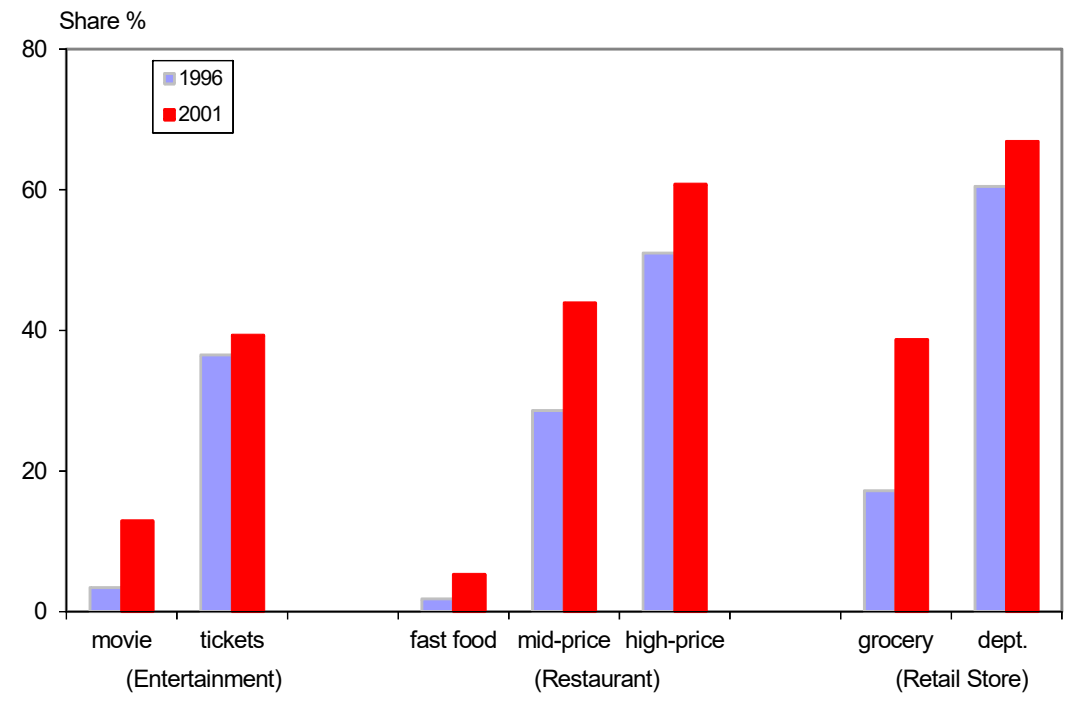

Figure A1(c): Percent of Transactions Using Payment Cards

A2. Derivation of Eqs. (L1) and (L2).

Under Assumptions F1 and F3, we can derive Eqs. (20) and (22) into

$$
\begin{gathered}
\alpha_{0}=\frac{k_{m}}{2 e^{\left(-\lambda I_{0}\right)}\left(1+\lambda I_{0}-k_{c}\right) Z_{0}}, \\
\lambda I_{0}=\frac{\left(\frac{1+\tau_{c}}{1+f_{c}}\right)^{\left(1-\alpha_{0}^{2}\right)} k_{c}}{\left(\frac{1+\tau_{c}}{1+f_{c}}\right)^{\left(1-\alpha_{0}{ }^{2}\right)}-\exp \left(2 \int_{\alpha_{0}}^{\min \left(\alpha_{1}, 1\right)} \alpha \ln \left(\frac{\left(1-\tau_{m}\right) \alpha}{\left(1-f_{m}\right) \alpha-\left(1+f_{c}\right) \alpha_{0} Z_{0}}\right) d \alpha\right)} .
\end{gathered}
$$

Equation (40) is exactly Eq. (L1). We can further rewrite Eq. (41) by noting that

$$
\begin{aligned}
& \int \alpha \ln \left(\frac{\left(1-\tau_{m}\right) \alpha}{\left(1-f_{m}\right) \alpha-\left(1+f_{c}\right) \alpha_{0} Z_{0}}\right) d \alpha \\
= & \frac{\alpha^{2}}{2} \ln \left(1-\tau_{m}\right)-\frac{1}{2} \alpha^{2} \ln \left(\left(1-f_{m}\right)-\frac{\alpha_{0} Z_{0}\left(1+f_{c}\right)}{\alpha}\right) \\
& +\frac{\alpha_{0} Z_{0}\left(1+f_{c}\right)}{2\left(1-f_{m}\right)} \alpha+\frac{\alpha_{0}^{2} Z_{0}^{2}\left(1+f_{c}\right)^{2}}{2\left(1-f_{m}\right)^{2}} \ln \left(\alpha-\frac{\alpha_{0} Z_{0}\left(1+f_{c}\right)}{\left(1-f_{m}\right)}\right) .
\end{aligned}
$$

Hence, we derive

$$
\begin{aligned}
& 2 \int_{\alpha_{0}}^{\frac{Z_{0}}{Z_{1}} \alpha_{0}} \alpha \ln \left(\frac{\left(1-\tau_{m}\right) \alpha}{\left(1-f_{m}\right) \alpha-\left(1+f_{c}\right) \alpha_{0} Z_{0}}\right) d \alpha \\
= & \alpha_{0}^{2}\left\{\ln \frac{1+f_{c}}{1+\tau_{c}}+\frac{Z_{0}\left(1+f_{c}\right)}{\left(1-f_{m}\right)}\left(\frac{Z_{0}}{Z_{1}}-1\right)+\frac{Z_{0}^{2}\left(1+f_{c}\right)^{2}}{\left(1-f_{m}\right)^{2}} \ln \left(\frac{\frac{Z_{0}}{Z_{1}}-\frac{Z_{0}\left(1+f_{c}\right)}{\left(1-f_{m}\right)}}{1-\frac{Z_{0}\left(1+f_{c}\right)}{\left(1-f_{m}\right)}}\right)\right\} .
\end{aligned}
$$


Equation (41) can then be rewritten into Eq. (L2) where

$$
s=\ln \frac{1+f_{c}}{1+\tau_{c}}+\frac{Z_{0}\left(1+f_{c}\right)}{\left(1-f_{m}\right)}\left(\frac{Z_{0}}{Z_{1}}-1\right)+\frac{Z_{0}^{2}\left(1+f_{c}\right)^{2}}{\left(1-f_{m}\right)^{2}} \ln \left(\frac{\frac{Z_{0}}{Z_{1}}-\frac{Z_{0}\left(1+f_{c}\right)}{\left(1-f_{m}\right)}}{1-\frac{Z_{0}\left(1+f_{c}\right)}{\left(1-f_{m}\right)}}\right) .
$$

\section{A3. Model Calibration: Monopoly Network}

Given functional form assumptions F1-F4, we can solve the model equilibrium under the monopoly network.

Within-Period Decision Within each period, the monopoly card network maximizes its profit as follows.

$$
\begin{gathered}
\pi(d ; \lambda)=\max _{f_{c}, f_{m}} \frac{e^{\left(-\lambda I_{0}\right)}}{\lambda}\left(1+\lambda I_{0}-k_{c}\right)\left(\frac{1-\alpha_{0}^{2}}{1+f_{c}}\right)\left(f_{c}+f_{m}-d\right) \\
\text { s.t. } \quad \alpha_{0}=\frac{k_{m}}{2 e^{\left(-\lambda I_{0}\right)}\left(1+\lambda I_{0}-k_{c}\right) Z_{0}}, \\
\alpha_{1}=\frac{Z_{0}}{Z_{1}} \alpha_{0} \quad \text { if } \quad f_{m} \leq \tau_{m}, \\
\lambda I_{0}=\frac{\left(\frac{1+\tau_{c}}{1+f_{c}}\right)^{\left(1-\alpha_{0}{ }^{2}\right)} k_{c}}{\left(\frac{1+\tau_{c}}{1+f_{c}}\right)^{\left(1-\alpha_{0}{ }^{2}\right)}-\exp \left(2 \int_{\alpha_{0}}^{\min \left(\alpha_{1}, 1\right)} \alpha \ln \left(\frac{\left(1-\tau_{m}\right) \alpha}{\left(1-f_{m}\right) \alpha-\left(1+f_{c}\right) \alpha_{0} Z_{0}}\right) d \alpha\right)}, \\
\tau_{c} \geq f_{c}, \quad \frac{1-f_{m}}{1+f_{c}} \geq \frac{1-\tau_{m}}{1+\tau_{c}} .
\end{gathered}
$$

For a given marginal cost $d$ and mean income $1 / \lambda$, we can derive $f_{c}^{*}, f_{m}^{*}, \lambda I_{0}^{*}, \alpha_{0}^{*}$. The corresponding maximum profit is

$$
\pi(d ; \lambda)=\frac{e^{\left(-\lambda I_{0}^{*}\right)}}{\lambda}\left(1+\lambda I_{0}^{*}-k_{c}\right)\left(\frac{1-\alpha_{0}^{* 2}}{1+f_{c}^{*}}\right)\left(f_{c}^{*}+f_{m}^{*}-d\right) .
$$

Conditioning on $d$, Eqs. (43-45) imply that the optimal values $\left(f_{m}^{*}, f_{c}^{*}, \lambda I_{0}^{*}, \alpha_{0}^{*}\right)$ are invariant to $\lambda$. Therefore, according to Eq. (47), the profit function is proportional to the mean income $\frac{1}{\lambda}$. Moreover, we can verify that $\lambda \pi$ is approximately linear in $d$ (as shown 
in Fig. A3 based on the model calibration), so that

$$
\pi(d ; \lambda)=\frac{1}{\lambda}\left(a_{0}-a_{1} d\right)
$$

where $a_{0}$ and $a_{1}$ are scalers determined by the model parameter values.

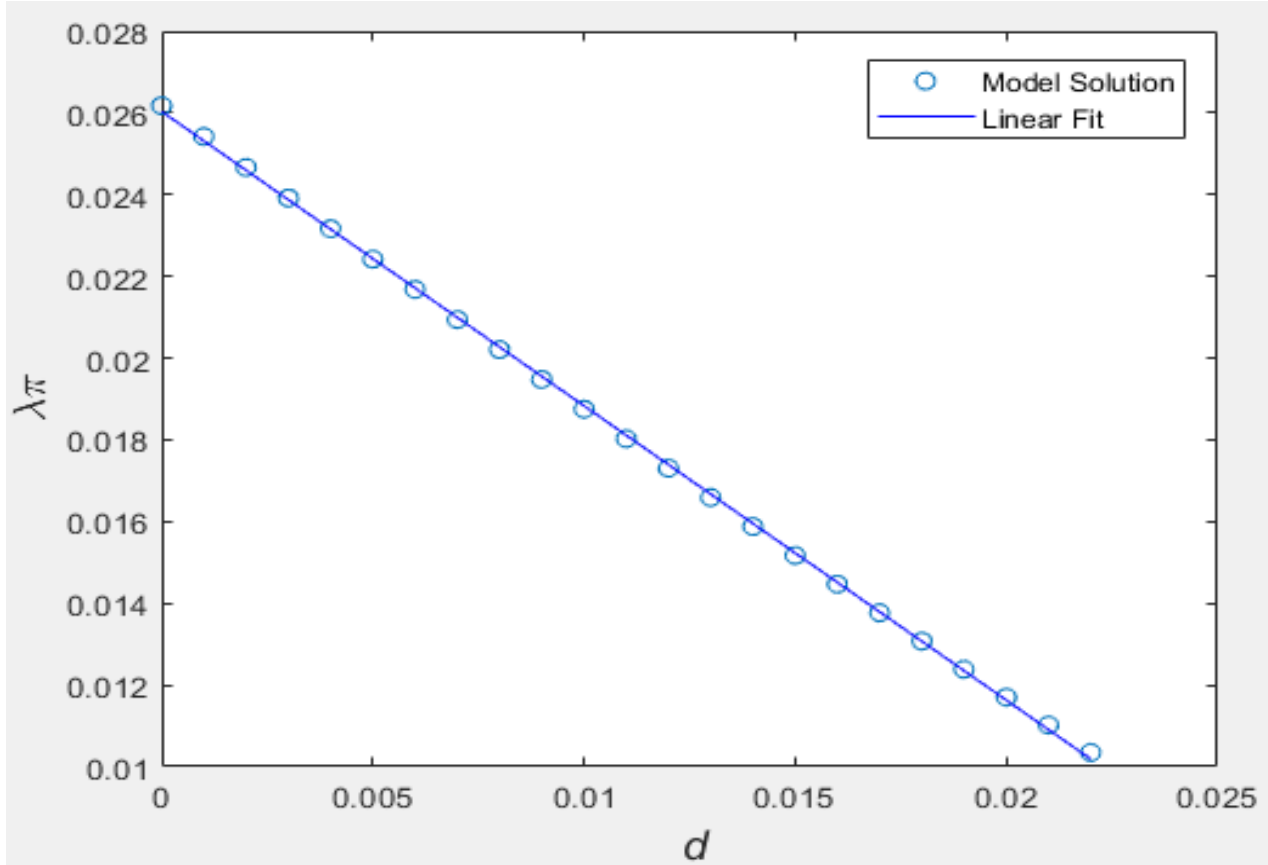

A3. Network Profit Function and Linear Fitting

Dynamic Decision We now add back the time subscript to each variable. The value function of the monopoly network is as follows.

$$
\begin{gathered}
V\left(d_{t} ; \lambda_{t}\right)=\max _{R_{t}} \pi\left(d_{t} ; \lambda_{t}\right)-R_{t}+\beta V\left(d_{t+1} ; \lambda_{t+1}\right) \\
\text { s.t. } \frac{1}{d_{t+1}}-\frac{1}{d_{t}}=\left(\frac{R_{t} \lambda_{t}}{\phi}\right)^{\gamma} d_{t}^{-\gamma-1} \\
\pi\left(d_{t} ; \lambda_{t}\right) \geq R_{t} .
\end{gathered}
$$

Assuming the budget constraint (50) never binds, the dynamic problem can be rewritten as

$$
V\left(d_{t} ; \lambda_{t}\right)=\max _{d_{t+1}} \frac{1}{\lambda_{t}}\left(a_{0}-a_{1} d_{t}\right)-\phi \frac{d_{t}}{\lambda_{t}}\left[\frac{d_{t}}{d_{t+1}}-1\right]^{\frac{1}{\gamma}}+\beta V\left(d_{t+1} ; \lambda_{t+1}\right)
$$


The first-order condition implies that

$$
\frac{\phi}{\gamma \lambda_{t}}\left[\frac{d_{t}}{d_{t+1}}-1\right]^{\frac{1}{\gamma}-1}\left[\frac{d_{t}}{d_{t+1}}\right]^{2}+\beta V^{\prime}\left(d_{t+1} ; \lambda_{t+1}\right)=0
$$

The envelope condition implies that

$$
V^{\prime}\left(d_{t} ; \lambda_{t}\right)=-\frac{a_{1}}{\lambda_{t}}-\frac{\phi}{\lambda_{t}}\left[\frac{d_{t}}{d_{t+1}}-1\right]^{\frac{1}{\gamma}}-\frac{\phi}{\gamma \lambda_{t}}\left[\frac{d_{t}}{d_{t+1}}-1\right]^{\frac{1}{\gamma}-1} \frac{d_{t}}{d_{t+1}}
$$

which suggests that

$$
V_{t+1}^{\prime}\left(d_{t+1} ; \lambda_{t+1}\right)=-\frac{a_{1}}{\lambda_{t+1}}-\frac{\phi}{\lambda_{t+1}}\left[\frac{d_{t+1}}{d_{t+2}}-1\right]^{\frac{1}{\gamma}}-\frac{\phi}{\gamma \lambda_{t+1}}\left[\frac{d_{t+1}}{d_{t+2}}-1\right]^{\frac{1}{\gamma}-1} \frac{d_{t+1}}{d_{t+2}}
$$

We can combine Eqs. (51) and (52) to get

$$
\frac{\phi}{\gamma \lambda_{t}}\left[\frac{d_{t}}{d_{t+1}}-1\right]^{\frac{1}{\gamma}-1}\left[\frac{d_{t}}{d_{t+1}}\right]^{2}=\frac{\beta a_{1}}{\lambda_{t+1}}+\frac{\beta \phi}{\lambda_{t+1}}\left[\frac{d_{t+1}}{d_{t+2}}-1\right]^{\frac{1}{\gamma}}+\frac{\beta \phi}{\gamma \lambda_{t+1}}\left[\frac{d_{t+1}}{d_{t+2}}-1\right]^{\frac{1}{\gamma}-1} \frac{d_{t+1}}{d_{t+2}}
$$

Calibrating $\gamma=1 / 2$, we can rewrite the above equation as

$$
\frac{2 \phi}{\lambda_{t}}\left[\frac{d_{t}}{d_{t+1}}-1\right]\left[\frac{d_{t}}{d_{t+1}}\right]^{2}=\frac{\beta a_{1}}{\lambda_{t+1}}+\frac{\beta \phi}{\lambda_{t+1}}\left[\frac{d_{t+1}}{d_{t+2}}-1\right]^{2}+\frac{2 \beta \phi}{\lambda_{t+1}}\left[\frac{d_{t+1}}{d_{t+2}}-1\right] \frac{d_{t+1}}{d_{t+2}}
$$

Given the constant income growth rate $\frac{\lambda_{t}}{\lambda_{t+1}}=g_{\lambda}$, we can solve for the balance growth path where $\frac{d_{t}}{d_{t+1}}=\frac{d_{t+1}}{d_{t+2}}=g_{d}$. Note that we can rewrite Eq. (53) as

$$
\frac{2 \phi}{g_{\lambda}}\left[g_{d}-1\right] g_{d}^{2}=\beta a_{1}+\beta \phi\left[g_{d}-1\right]^{2}+2 \beta \phi\left[g_{d}-1\right] g_{d}
$$

and solve for a constant cost declining rate $g_{d}$. Based on $g_{d}$, we can then solve dynamic paths of all the endogenous variables in the model. We can also verify that the budget constraint (50) never binds.

\section{A4. Model Calibration: Ramsey Social Planner}

Given functional form assumptions F1-F4, we can solve the model equilibrium under 
the Ramsey social planner.

\section{Within-Period Decision}

Within each period, for a given income-scaled $\mathrm{R} \& \mathrm{D}$ expenditure $\lambda R$, the Ramsey social planner maximizes consumer welfare as follows.

$$
\begin{aligned}
& U(d, \lambda R ; \lambda)=\operatorname{Max}_{f_{c}, f_{m}} \int_{I_{0}}^{\infty} U_{I, d}^{d} \lambda e^{-\lambda I} d I+\int_{0}^{I_{0}} U_{I, d}^{h} \lambda e^{-\lambda I} d I \\
& \text { s.t. } U_{I, d}^{d}=U_{I, h} \exp \left(\ln U_{I, d}^{d}-\ln U_{I, h}\right) \\
& =I \overline{U_{h}} \exp \left\{\begin{array}{c}
\int_{\alpha_{0}}^{\min \left(\alpha_{1}, 1\right)} 2 \alpha \ln \left(\frac{p_{\alpha, h}}{p_{\alpha, d}}\right) d \alpha+\int_{\min \left(\alpha_{1}, 1\right)}^{1} 2 \alpha \ln \left(\frac{p_{\alpha, h}}{p_{\alpha, d}}\right) d \alpha \\
+\left(1-\alpha_{0}^{2}\right) \ln \left(\frac{1+\tau_{c}}{1+f_{c}}\right)+\ln \left(\frac{\lambda I-k_{c}}{\lambda I}\right)
\end{array}\right\}, \\
& U_{I, d}^{h}=U_{I, h} \exp \left(\ln U_{I, d}^{h}-\ln U_{I, h}\right)=I \overline{U_{h}} \exp \left\{\int_{\min \left(\alpha_{1}, 1\right)}^{1} 2 \alpha \ln \left(\frac{p_{\alpha, h}}{p_{\alpha, d}}\right) d \alpha\right\}, \\
& \left(\frac{p_{\alpha, h}}{p_{\alpha, d}}\right)_{1 \geq \alpha \geq \min \left(\alpha_{1}, 1\right)}=\frac{\frac{1-f_{m}}{1+f_{c}} e^{-\lambda I_{0}}\left(1+\lambda I_{0}-k_{c}\right)+\frac{1-\tau_{m}}{1+\tau_{c}}\left[1-e^{-\lambda I_{0}}\left(1+\lambda I_{0}\right)\right]-\frac{k_{m}}{2 \alpha}}{\frac{1-\tau_{m}}{1+f_{c}} e^{-\lambda I_{0}}\left(1+\lambda I_{0}-k_{c}\right)+\frac{1-\tau_{m}}{\left(1+\tau_{c}\right)}\left[1-e^{-\lambda I_{0}}\left(1+\lambda I_{0}\right)\right]}, \\
& \left(\frac{p_{\alpha, h}}{p_{\alpha, d}}\right)_{\min \left(\alpha_{1}, 1\right)>\alpha \geqslant \alpha_{0}}=\frac{\left(\frac{1-f_{m}}{1+f_{c}}\right) e^{-\lambda I_{0}}\left(1+\lambda I_{0}-k_{c}\right)-\frac{k_{m}}{2 \alpha}}{\frac{1-\tau_{m}}{1+f_{c}} e^{-\lambda I_{0}}\left(1+\lambda I_{0}-k_{c}\right)}, \\
& \alpha_{0}=\frac{k_{m}}{2 e^{\left(-\lambda I_{0}\right)}\left(1+\lambda I_{0}-k_{c}\right) Z_{0}} \\
& \alpha_{1}=\frac{Z_{0}}{Z_{1}} \alpha_{0} \quad \text { if } \quad f_{m} \leq \tau_{m} \\
& \lambda I_{0}=\frac{\left(\frac{1+\tau_{c}}{1+f_{c}}\right)^{1-\alpha_{0}^{2}} k_{c}}{\left(\frac{1+\tau_{c}}{1+f_{c}}\right)^{1-\alpha_{0}^{2}}-\exp \left(2 \int_{\alpha_{0}}^{\min \left(\alpha_{1}, 1\right)} \alpha \ln \left(\frac{\left(1-\tau_{m}\right) \alpha}{\left(1-f_{m}\right) \alpha-\left(1+f_{c}\right) \alpha_{0} Z_{0}}\right) d \alpha\right)}, \\
& \tau_{c} \geq f_{c}, \quad \frac{1-f_{m}}{1+f_{c}} \geq \frac{1-\tau_{m}}{1+\tau_{c}}
\end{aligned}
$$




$$
\lambda \pi=e^{\left(-\lambda I_{0}\right)}\left(1+\lambda I_{0}-k_{c}\right)\left(\frac{1-\alpha_{0}^{2}}{1+f_{c}}\right)\left(f_{c}+f_{m}-d\right) \geq \lambda R
$$

For a given marginal cost $d$ and the profit target $\lambda R$, we can derive $f_{c}^{*}, f_{m}^{*}, \lambda I_{0}^{*}, \alpha_{0}^{*}$. The corresponding maximum consumer welfare is

$$
\begin{aligned}
U(d, \lambda R ; \lambda) & =\int_{I_{0}}^{\infty} U_{I, d}^{d} \lambda e^{-\lambda I} d I+\int_{0}^{I_{0}} U_{I, d}^{h} \lambda e^{-\lambda I} d I \\
& =\frac{\overline{U_{h}}}{\lambda}\left\{\int_{\lambda I_{0}}^{\infty} \lambda I \exp \{\cdot\} e^{-\lambda I} d \lambda I+\exp \{*\} \int_{0}^{\lambda I_{0}} \lambda I e^{-\lambda I} d \lambda I\right\},
\end{aligned}
$$

where $\exp \{\cdot\}$ and $\exp \{*\}$ are given in Eqs. (54) and (55), respectively.

We can again verify that conditioning on $d$ and $\lambda R$, the optimal values $\left(f_{c}^{*}, f_{m}^{*}, \lambda I_{0}^{*}\right.$, $\alpha_{0}^{*}$ ) are invariant to $\lambda$, so according to Eq. (56) the welfare function is proportional to the mean income $\frac{1}{\lambda}$. Moreover, we can verify that $\lambda U$ is approximately linear in $d$ and $\lambda R$ (as shown in Fig. A4 based on the model calibration). Therefore, the welfare function can be simplified as

$$
U(d, \lambda R ; \lambda)=\frac{1}{\lambda}\left(b_{0}-b_{1} d-b_{2} \lambda R\right),
$$

where $b_{0}, b_{1}$ and $b_{2}$ are scalers determined by the model parameter values.

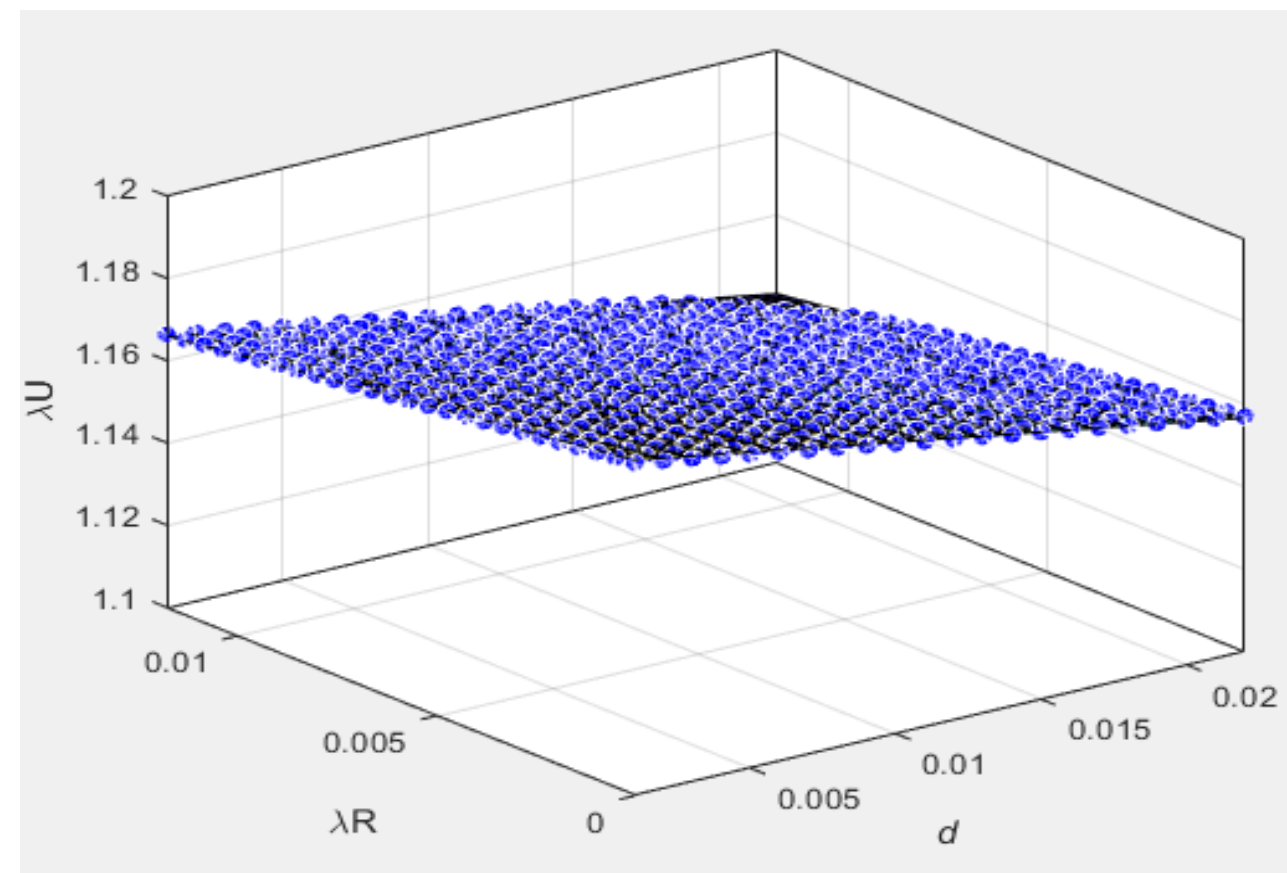

A4. Consumer Welfare Function and Linear Fitting 
Dynamic Decision We now add back the time subscript to each variable. The value function of the Ramsey social planner is as follows.

$$
\begin{gathered}
V\left(d_{t} ; \lambda_{t}\right)=\max _{R_{t}} U\left(d_{t}, \lambda_{t} R_{t} ; \lambda_{t}\right)+\beta V\left(d_{t+1} ; \lambda_{t+1}\right), \\
\text { s.t. } \frac{1}{d_{t+1}}-\frac{1}{d_{t}}=\left(\frac{R_{t} \lambda_{t}}{\phi}\right)^{\gamma} d_{t}^{-\gamma-1} .
\end{gathered}
$$

The dynamic problem can be rewritten as

$$
V\left(d_{t} ; \lambda_{t}\right)=\max _{d_{t+1}} \frac{1}{\lambda_{t}}\left(b_{0}-b_{1} d_{t}-b_{2} \lambda_{t} R_{t}\right)-b_{2} \phi \frac{d_{t}}{\lambda_{t}}\left[\frac{d_{t}}{d_{t+1}}-1\right]^{\frac{1}{\gamma}}+\beta V\left(d_{t+1} ; \lambda_{t+1}\right)
$$

The first-order condition implies that

$$
b_{2} \phi \frac{d_{t}^{2}}{\gamma \lambda_{t} d_{t+1}^{2}}\left[\frac{d_{t}}{d_{t+1}}-1\right]^{\frac{1}{\gamma}-1}+\beta V^{\prime}\left(d_{t+1} ; \lambda_{t+1}\right)=0
$$

The envelope condition implies that

$$
V^{\prime}\left(d_{t} ; \lambda_{t}\right)=\frac{1}{\lambda_{t}}\left(-b_{1}\right)-\frac{b_{2} \phi}{\lambda_{t}}\left[\frac{d_{t}}{d_{t+1}}-1\right]^{\frac{1}{\gamma}}-b_{2} \phi \frac{d_{t}}{d_{t+1} \gamma \lambda_{t}}\left[\frac{d_{t}}{d_{t+1}}-1\right]^{\frac{1}{\gamma}-1}
$$

which suggests that

$$
V^{\prime}\left(d_{t+1} ; \lambda_{t+1}\right)=\frac{1}{\lambda_{t+1}}\left(-b_{1}\right)-\frac{b_{2} \phi}{\lambda_{t+1}}\left[\frac{d_{t+1}}{d_{t+2}}-1\right]^{\frac{1}{\gamma}}-b_{2} \phi \frac{d_{t+1}}{d_{t+2} \gamma \lambda_{t+1}}\left[\frac{d_{t+1}}{d_{t+2}}-1\right]^{\frac{1}{\gamma}-1}
$$

Combining Eqs. (58) and (59), we get

$$
b_{2} \phi \frac{d_{t}^{2}}{\gamma \lambda_{t} d_{t+1}^{2}}\left[\frac{d_{t}}{d_{t+1}}-1\right]^{\frac{1}{\gamma}-1}=\frac{\beta}{\lambda_{t+1}} b_{1}+\frac{\beta b_{2} \phi}{\lambda_{t+1}}\left[\frac{d_{t+1}}{d_{t+2}}-1\right]^{\frac{1}{\gamma}}+b_{2} \phi \frac{\beta d_{t+1}}{d_{t+2} \gamma \lambda_{t+1}}\left[\frac{d_{t+1}}{d_{t+2}}-1\right]^{\frac{1}{\gamma}-1} .
$$

Calibrating $\gamma=1 / 2$, we can rewrite the above equation as

$$
2 b_{2} \phi \frac{d_{t}^{2}}{\lambda_{t} d_{t+1}^{2}}\left[\frac{d_{t}}{d_{t+1}}-1\right]=\frac{\beta}{\lambda_{t+1}} b_{1}+\frac{\beta b_{2} \phi}{\lambda_{t+1}}\left[\frac{d_{t+1}}{d_{t+2}}-1\right]^{2}+2 b_{2} \phi \frac{\beta d_{t+1}}{d_{t+2} \lambda_{t+1}}\left[\frac{d_{t+1}}{d_{t+2}}-1\right]
$$

Given the constant income growth rate $\frac{\lambda_{t}}{\lambda_{t+1}}=g_{\lambda}$, we can solve for the balance growth 
path $\frac{d_{t}}{d_{t+1}}=\frac{d_{t+1}}{d_{t+2}}=g_{d}$. Note that Eq. (60) can be rewritten as

$$
\frac{2 \phi b_{2}}{g_{\lambda}}\left[g_{d}-1\right] g_{d}^{2}=\beta b_{1}+\beta \phi b_{2}\left[g_{d}-1\right]^{2}+2 b_{2} \beta \phi\left[g_{d}-1\right] g_{d},
$$

and we can solve for the constant cost declining rate $g_{d}$. Based on $g_{d}$, we can then solve dynamic paths of all the endogenous variables in the model. 